\title{
PARA UMA BIBLIOGRAFIA DA HISTÓRIA DA LÍNGUA PORTUGUESA
}

\author{
José Pereira da Silva (UERJ) \\ pereira@filologia.org.br
}

Apesar de extremamente incompleta e ainda não plenamente atualizada, este trabalho pretende apresentar uma importante contribuição para os estudos diacrônicos da língua portuguesa, a partir do qual se poderão desenvolver numerosos e importantes trabalhos de história da língua portuguesa.

Promete-se para brevemente, uma ampliação e atualização desse texto para que se possa ter uma boa bibliografia atualizada desta especialidade dos estudos da língua portuguesa: a sua história (externa e interna).

Além de outras fontes importantes que ainda não foram consultadas, pretendemos completar esta pequena bibliografia com a busca de informações oferecidas pelos próprios autores na Plataforma Lattes do $\mathrm{CNPq}$ e fazer uma revisão geral para uniformizar os verbetes, segundo as normas da ABNT para referências bibliográficas em trabalhos acadêmicos.

Para este esboço, três bases foram fundamentais: o relatório da disciplina História da Língua Portuguesa, da professora Maria Teresa Brocardo (2006), a Gramática do Português Brasileiro, do professor Ataliba Teixeira de Castilho (2010) e a página de busca interna do Círculo Fluminense de Estudos Filológicos e Linguísticos (http://www.filologia.org.br/buscainterna.html).

Agradecemos qualquer sugestão ou crítica e, em troca, reforçamos nossa promessa de oferecer uma bibliografia melhor dentro de algum tempo.

Rio de Janeiro, 22 de novembro de 2010.

$\underline{\text { José Pereira da Silva }}$ 
1. ACADEMIA Brasileira de Letras. Vocabulário ortográfico da língua portuguesa. 5. ed. São Paulo: Global, 2009.

2. AGUIAR, M. R. As reformas ortográficas da língua portuguesa: uma análise histórica, linguística e ideológica. Filologia $e$ Linguística Portuguesa 9. São Paulo: USP/FFLCH, 2007, p. 11-26.

3. AGUILERA, V. A. (Org.). A geolinguística no Brasil: caminhos e perspectivas. Londrina: UEL, 1998.

$4 . \quad$ _. Para a história do português brasileiro: Vozes, veredas, voragens. Londrina: EDUEL, 2009, v. VII, 2 t.

5. ALKMIN, M. Fontes para o estudo do português setecentista e oitocentista em Minas Gerais. In: DUARTE; CALLOU (Orgs., 2002, p. 87-92).

6. ALKMIN, T. M. A variedade linguística de negros e escravos: um tópico da história do português no Brasil. In: MATTOS E SILVA (Org., 2001, tomo 2, p. 317-336).

7. _. Para a história do português brasileiro: v. III - Novos estudos. São Paulo: Humanitas; Campinas: UNICAMP, 2002.

8. ANDRADE, A. C. S. de. Diacronia e sincronia: abordagem e interações. Disponível em:

http://www.filologia.org.br/viiicnlf/anais/caderno1007.html. Acesso em: 2010.

9. ARACIL, LL. V. Do latim às línguas nacionais: introdução à história social das línguas europeias. Organização, prefácio, transcrição e tradução de Ângelo Cristóvão. Santiago de Compostela: Associação de Amizade Galiza-Portugal, 2004.

10. AUROUX, S. A revolução tecnológica da gramaticalização. Campinas: UNICAMP, 1992.

11. AZEVEDO, P. Testamento em português de D. Affonso II (1214). Revista Lusitana 8, 1903-1905, p. 80-84.

12. __ Archivo Historico Portuguez IV-VII, 1906-1909. [Reeditado em Lisboa: Colibri, 2003]. 
13. U Uma versão portuguesa da história natural das aves do séc. XIV". Revista Lusitana 25, 1923-1925, p. 128-147

14. BAGNO, M. A língua de Eulália: novela sociolinguística. São Paulo: Contexto, 1997.

15. ___ Nada na língua é por acaso: por uma pedagogia da variação linguística. São Paulo: Parábola, 2007.

16. BANZA, A. P. A linguagem dos documentos em português da Chancelaria de D. Afonso III. Dissertação de Mestrado. Lisboa: Universidade de Lisboa, Faculdade de Letras, 1992.

17. BARBOSA, A. G. Normas cultas e normas vernáculas: a encruzilhada histórico-diacrônica nos estudos sobre português brasileiro. In: CASTILHO et alii (Orgs., 2007, p. 499-512.

18. _. Para uma história do português colonial. Aspectos linguísticos em cartas de comércio. Rio de Janeiro: UFRJ, 1999, 2 v.

19. _ _ _ _ LOPES, C. R. S.; CALLOU, D. M. I. Para uma história do português do Brasil - RJ. Disponível em:

http://www.letras.ufrj.br/phpb-ri. Acesso em: 20-09-2010.

20. BARCIA, L.; SILVA, Andreza. Vossa Mercê, você, vós, ou tu? A flutuação de formas em cartas cariocas dos séculos XVIII e XIX. Ao pé da Letra. Disponível em:

http://www.letras.ufrj.br/laborhistorico/Andreza,\%20Lucia .pdf. Acesso em: 20-09-2010.

21. BARRETO, T. M. M. Gramaticalização das conjunções na história do português. Salvador: UFBA, 1999.

22. BARROS, J. Gramática da língua portuguesa. Reprod. facsim. org. por Maria Leonor Buescu. Lisboa: FLL, 1971.

23. BASSETTO, B. F. Elementos de filologia românica: história externa das línguas. 2. ed. São Paulo: Edusp, 2005. [1 ed., 2001].

24. BASTOS, N. B.; IÓRIO, P. S. L.; NOGUEIRA, S. M. In: HENRIQUES, C. C.; SIMÕES, D. (Org.). Língua portuguesa: 
reflexões sobre descrição, pesquisa e ensino. Rio de Janeiro: Europa, 2005, p. 124-135.

25. BASTOS, N. B.; PALMA, D. V. (Orgs.). História entrelaçada: a construção de gramáticas e o ensino de língua portuguesa nos séculos XVI e XIX. Rio de Janeiro: Lucerna, 2004.

26. História entrelaçada 2: a construção de gramáticas e o ensino de língua portuguesa na primeira metade do século XX. Rio de Janeiro: Lucerna, 2006.

27. et alii. História entrelaçada 3: a construção de gramáticas e o ensino de língua portuguesa na segunda metade do século XX. Rio de Janeiro: Lucerna, 2008.

28. BASTOS, N. M. O. B. Sintaxe do português: de uma abordagem histórica para uma perspectiva inovadora. In: VALENTE, A. (Org.). Aulas de português: perspectivas inovadoras. Petrópolis: Vozes, 1999, p. 257-268.

29. BECHARA, E. As fases da língua portuguesa escrita. In: KREMER, Dieter (ed.) Actes du XVIIIe Congrès International de Linguistique et Philologie Romanes (Trier 1986) Tome III, Tübingen, Max Niemeyer, 1991, p. 68-76.

30. __ As fases históricas da língua portuguesa: tentativa de proposta de nova periodização. In: SILVA, J. P. (Org.). Cinco teses de Evanildo Bechara. Rio de Janeiro: Botelho, 2008, cdrom.

31. _ . O futuro românico: considerações em torno de sua origem. In: SILVA, J. P. (Org.). Cinco teses de Evanildo Bechara. Rio de Janeiro: Botelho, 2008, cd-rom.

32. BENATTI, M. Aculturação linguística numa colônia de imigrantes italianos de Santa Catarina, Brasil. Lorena: Faculdade Salesiana de Filosofia, 1974.

33. BENVENISTE, É. O vocabulário das instituições indoeuropeias. Campinas: UNICAMP, 1995, $2 \mathrm{v}$.

34. BERLINCK, R. a. A construção V SN1 no português brasileiro: uma visão diacrônica do fenômeno da ordem. In: TARALLO (Org., 1989, p. 95-112). 
35. BERTOLOTTI, V. et alii (Orgs.). Documentos para la historia del portugués en el Uruguay: Montevideo: Faculdad de Humanidades Y Ciencias de la Educación de la Universidad de la República, 2005.

36. BIDERMAN, M. T; NASCIMENTO, M. F. B. Unidade e diversidade: o vocabulário da língua oral em Portugal e no Brasil. In: LOPES, A. C. M.; MARTINS, C. (Eds.). Actas do XIV Encontro Nacional da Associação Portuguesa de Linguística (Aveiro 1998), vol. I. Braga: Gráfica de Coimbra, 1999, p. 175193.

37. BLUTEAU, R. Vocabulario portuguez e latino. Vols. I-IV, Coimbra: Colegio das Artes, 1712-1713; Vols. V-VIII, Lisboa: Pascoal da Sylva, 1716-1721. [Completo em cd-rom: Rio de Janeiro: UERJ/DINFO, 2000].

$38 . \quad$ Suplemento ao Vocabulario portuguez e latino. Vol. I, Lisboa: Joseph Antonio da Sylva; Vol. II, Lisboa: Patriarcal Officina da Musica, 1728.

39. BOLÉO, M. P. Filologia e história: a emigração açoriana para o Brasil. Com documentos inéditos. Biblos XX, separata, Coimbra, 1945.

40. Introdução ao estudo da filologia portuguesa. Lisboa: Revista de Portugal, 1946.

41. O estudo dos falares portugueses antigos e modernos e sua contribuição para a história da língua. In: Estudos de Linguística Portuguesa e Românica. Coimbra: Acta Universitatis Conimbrigensis, vol. I, t. I, 1974, p. 289-307. . Os estudos de linguística românica na Europa e na América de 1939 a 1948. Coimbra: Casa do Castelo, 1951.

43. __ SILVA, M. H. S. O Mapa dos dialectos e falares de Portugal Continental. Boletim de Filologia 20 (Actas do IX Congresso Internacional de Linguística Românica, Lisboa 1959. Vol. III. Lisboa: Centro de Estudos Filológicos) 1962, p. 85-112 [transcr. em CASTRO, I. 1991, p. 43-77]. 
44. BORTOLANZA, J. Cantiga em diacronia. Disponível em: http://www.filologia.org.br/revista/artigo/7(21)05.htm. Acesso em: 10-09-2010.

45. __ A diacronia na obra de Said Ali. Disponível em: http://www.filologia.org.br/ixcnlf/17/02.htm. Acesso em: 10-09-2010.

46. - O latim e o ensino de português. Disponível em: http://www.filologia.org.br/revista/artigo/6(18)7785.html. Acesso em: 10-09-2010.

47. BOURCIEZ, É. Latim: elemento número 1 da linguística românica. Tradução de José Pereira da Silva. Prefácio de Maria Antônia da Costa Lobo. Rio de Janeiro: CiFEFiL, 2000.

48. BRITO, A. M. Concordância, estrutura de frase e movimento do verbo no Português Europeu, no Português Brasileiro e no Português de Moçambique. In: FARIA, I. H. (Org.), Lindley Cintra. Homenagem ao Homem, ao Mestre e ao Cidadão. Lisboa: Cosmos / FLL, 1999, p. 333-365.

49. BRITO, A. M.; FIGUEIREDO, O.; BARROS, C. (Orgs.). Linguística histórica e história da língua portuguesa. Actas do Encontro de Homenagem a Maria Helena Paiva. Porto: Faculdade de Letras da Universidade do Porto, 2003.

50. BROCARDO, M. T. História da língua portuguesa: relatório da disciplina. LISBOA: UNL, 2006. Disponível em:

http://www.clunl.edu.pt/resources/docs/grupos/gramatica/equip a/teresabrocardo/brocardo relat\%C3\%B3riohlp_2006.pdf. Acesso em: 26-09-2010.

51. . Livro de linhagens do Conde D. Pedro. Edição do Fragmento manuscrito da Biblioteca da Ajuda (século XIV). Lisboa: IN-CM, 2006.

52. . Sobre o português médio. In: GÄRTNER et alii (Eds., 1999, p. 107-125).

53. . Sobre a mudança - $u d o>$-ido nas formas de particípio passado em português. In: MATEUS, M. H.; CORREIA, C. 
(Eds.). Saberes no tempo. Homenagem a Maria Henriqueta Costa Campos. Lisboa: Colibri, 2002, p. 137-145.

54. Haver e ter em português medieval. Dados de textos dos séculos XIV e XV. Revue de Linguistique Romane 70, 2006, p. 95-122.

55.

Sobre periodização da história do português europeu (contributo para uma discussão). Iberoromania 62, 2006, p. 97117.

56. ; EMILIANO, A. Considerações sobre a edição de fontes para a história da língua portuguesa. In: RAPOSO, E. P.; SHARRER, H (Orgs.), Santa Barbara Portuguese Studies VI, 2006.

57. BUENO, F. S. Formação histórica da língua portuguesa. Rio de Janeiro: Acadêmica, 1995.

58. BUESCU, M. L. C. (1984) Historiografia da língua portuguesa (século XVI). Lisboa, Sá da Costa, 1984.

59. CAETANO, M. C; BROCARDO, M. T. O prefixo des- num texto português do século XV - contribuição para um estudo de morfologia derivacional diacrónica. In: LOPES, A. C. M.; MARTINS, C. (Eds.). Actas do XIV Encontro Nacional da Associação Portuguesa de Linguística (Aveiro 1998), Vol. I, Braga: Gráfica de Coimbra, 1998, p. 213-225.

60. CAFEZEIRO, E. Sobre o nexo em alguns textos do português colonial. In: DUARTE; CALLOU (Orgs., 2002, p. 207-222).

61. CAllOU, D.; LEITE, Y.; COUTINHO, L.; CUNHA, C. Um problema na fonologia do português: variação das vogais pretônicas. In: PEREIRA; PEREIRA. [Eds.). Miscelânea de Estudos Linguísticos, Filológicos e Literários. In Memoriam Celso Cunha. Rio de Janeiro: Nova Fronteira, 1995, p. 59-70.

62. ; MORAES, J. Processos de mudança no português do Brasil: variáveis sociais. In: CASTRO, I; DUARTE, I. (Eds.). Razões e Emoção, Miscelânea de estudos em homenagem a Maria Helena Mira Mateus, Vol. I. Lisboa: Imprensa Nacional-Casa da Moeda, 2003, p. 87-114. 
63. CÂMARA JR., J. M. História e estrutura da língua portuguesa. Rio de Janeiro: Padrão, 1976.

64. CAMBRAIA, C. N. Subsídios para a fixação de normas de transcrição de textos para estudos linguísticos. In: MATTOS E SILVA (Org., 2001, t. 2, p. 531-534).

65. CAMPOS, G. L. A língua portuguesa em Timor Leste: relevância sociolinguística. Disponível em:

http://www.filologia.org.br/viiifelin/08.htm. Acesso em: 1009-2010.

66. CARDEIRA, E. M. C. M. Entre o português antigo e o português clássico. Lisboa: Imprensa Nacional/Casa da Moeda, 2005.

67. CARDEIRA, E.; FERNANDES, M. A. As terminações nasais nas Actas das Vereações de Loulé (séculos XIV-XV). In: LOPES, A. C. M.; MARTINS, C. (Eds.). Actas do XIV Encontro Nacional da Associação Portuguesa de Linguística (Aveiro 1998). Vol. I, Braga: Gráfica de Coimbra, 1999, p. 251-263.

68. CARDOSO, S. A. M.; MOTA, J.; MATTOS E SILVA, R. V. (Orgs.). Quinhentos anos de história linguística do Brasil. Salvador: Fundo de Cultura da Bahia, 2006.

69. CARRASCO GONZÁLEZ, J. A língua portuguesa na Estremadura Espanhola: o caso de Valencia de Alcántara. In: DUARTE, I.; LEIRIA, I. (Eds.). Actas do Congresso Internacional sobre o Português (Lisboa, 1994), vol. III. Lisboa: Colibri, 1996, p. 57-73.

70. CARREGAL, A. A. D. Análise de algumas das notas linguísticas de Angelo Colocci aos cancioneiros galego-portugueses $B$ e $V$. Disponível em: http://www.filologia.org.br/revista/artigo/7(21)05.htm. Acesso em: 10-09-2010.

71. CARTER, H. H. Cancioneiro da Ajuda. Edição diplomática. New York: London, 1941.

$72 . \quad$ _ A fourteenth-century Latin-Old Portuguese Verb Dictionary. Romance Philology 6, 1952-1953, p. 71-103. 
73. . The Portuguese book of Joseph of Arimathea. Chapel Hill: The University of North Caroline Press, 1967.

74. CARVALHO, C. de. História interna da língua portuguesa. Disponível em: http://www.filologia.org.br/abf/volume2/numero2/05.htm . Acesso em: 10-09-2010.

75. CARVALHO, M. J. Do português arcaico ao português moderno: contributos para uma nova proposta de periodização. Coimbra: Faculdade de Letras da Universidade de Coimbra, 1996.

76. CASAGRANDE, A. A negação no português arcaico. São José do Rio Preto: Faculdade de Filosofia, Ciências e Letras, 1972.

77. CASTILHO, A. T. de. Corpus diacrônico do português brasileiro. Disponível em:

http://www.fl.ul.pt/pessoais/ailp/encontro/ataliba.htm. Acesso em: 20-09-2010.

78. ___ Estruturalismo, história e aspecto verbal. Alfa 4, 1963, p. 138-166.

79. . História do português brasileiro. In: . Gramática do português brasileiro. São Paulo: Contexto, 2010, p. 169-195.

80. _ Historiando o português brasileiro: história das línguas: variedades, gramaticalização, discursos. Blaubeuren: Universität Tübingen, 2003. Disponível em:

http://www.letras.ufmg.br/profs/jania/dados/arquivos/Histo riando....pdf. Acesso em: 09/09/2010.

81. __ Para a história do português de São Paulo. Revista Portuguesa de Filologia 23, 1999-2000, p. 29-70).

82. . Para um programa de pesquisas sobre a história social do português de São Paulo. In: MATTOS E SILVA (Org., 2001, t. 2, p. 337-370).

83. _ Projeto de história do português de São Paulo In: CASTILHO (Org., 1998, p. 61-78). 
84. . (Org.). Para a história do português brasileiro. V. I: Primeiras ideias. São Paulo: Humanitas, 1998.

85. . (Org.). História do português paulista. Campinas: IEL/UNICAMP, 2009.

86. CASTILHO, C. M. M. A concordância nos inventários do séc. XVII. In: CASTILHO (Org., 2009, p. 333-350).

87. . Locativos, fóricos, articuladores discursivos e conjunções no português medieval. Gramaticalização de "ende/en" e "porende/ porém". Filologia e Linguística Portuguesa 6, 2004, p. $53-100$.

88.

O processo de redobramento sintático no português medieval: o redobramento pronominal e a formação das perífrases de estar + ndo/-r. Tese de doutorado. Campinas: UNICAMP, 2005.

89. Primeiras histórias sobre a diacronia do dequeísmo: o clítico locativo "en" e o dequeísmo das orações relativas no português medieval. In: LOBO et alii (Orgs., 2006, p. 183-222).

90. __ Seria quatrocentista a base do português brasileiro? In: MATTOS E SILVA (Org., 2001, t. 1, p. 57-90).

91. CASTRO, I. Curso de história da língua portuguesa. (Com a colaboração de Rita Marquilha e J. Léon Acosta). Lisboa: Universidade Aberta, 1991.

92. A elaboração da língua portuguesa no tempo do Infante D. Pedro. Biblos 69 (Actas do Congresso Comemorativo do $6^{\circ}$ Centenário do Infante D. Pedro), 1993, p. 97-106.

93. A primitiva produção escrita em português. In: FERNÁNDEZ CATÓN, J. M. (Ed.). Orígenes de las lenguas romances en el Reino de León. Siglos IX-XII. Léon: Centro de Estudios e Investigación San Isidoro, vol. II, 2004, p. 69-97.

94. __ Galegos e Mouros. Cadernos da Cátedra de Estudos Galegos 2. Lisboa: Cátedra de Estudos Galegos da Universidade de Lisboa / Colibri, 2002. 
95. boa: Colibri, 2006.

96. . Introdução à história do português: Geografia da língua. Português antigo. Lisboa: Colibri, 2004.

97. _ Livro de José de Arimateia. Estudo e edição do Cod. ANTT 643. Universidade de Lisboa, Faculdade de Letras, 1984. (Diss. de Doutoramento)

98. O linguista e a fixação da norma. In: MENDES, A.; FREITAS, T. (Eds.). Actas do XVIII Encontro Nacional da Associação Portuguesa de Linguística (Porto 2002). Lisboa: Colibri, 2003, p. 11-24.

99. O português médio segundo Cintra (nuga bibliográfica). In: FARIA, I. H. (Org.) Lindley Cintra. Homenagem ao Homem, ao Mestre e ao Cidadão. Lisboa, Cosmos / FLL, 1999, p. 367-370.

100. _. Para uma caracterização do português clássico. In: CUARTE; LEIRIA (Eds., 1996, p. 135-150).

101. __ Para uma história do português clássico. In: DUARTE, I.; LEIRIA, I. (Eds.). Actas do Congresso Internacional sobre o Português (Lisboa, 1994). Vol. II. Lisboa: Colibri, 1996, p. 135-150.

102. Sobre a data da Introdução na Península Ibérica do ciclo arturiano da post-vulgata. Boletim de Filologia 28 (Homenagem a Manuel Rodrigues Lapa, Vol. I), 1983, p. 81-98.

103. et alii. Mesa redonda [sobre] a antiga documentação de Portugal. In: FREITAS, T.; MENDES, A. (Eds.). Actas do XIX Encontro Nacional da Associação Portuguesa de Linguística (Lisboa 2003). Lisboa: Colibri, 2004, p. 47-83.

104. (Dir.). História da língua portuguesa. Disponível em:

http://cvc.instituto-camoes.pt/conhecer/bases-

tematicas/historia-da-lingua-portuguesa.html. Acesso em: 10-09-2010.

105. .; DUARTE, I; LEIRIA, I. (Orgs.). A demanda da ortografia portuguesa. Comentários do Acordo Ortográfico de 
1986 e subsídios para a compreensão da questão que se lhe seguiu. Lisboa: João Sá da Costa, 1987.

106. CAVALCANTI, C. Origem e formação da língua portuguesa. Disponível em: http://www.filologia.org.br/ixcnlf/5/15.htm. Acesso em: 10-09-2010.

107. CAVALIERE, R. (Org.). Entrelaços e entre textos: miscelânea em homenagem a Evanildo Bechara. Rio de Janeiro: Nova Fronteira, 2008.

108. CEPEDA, I. V. Bibliografia da Prosa Medieval em Língua Portuguesa (subsídios). Lisboa: IBNL, 1995.

109. __ Vidas e paixões dos apóstolos (Bernardo de Brihuega). Edição crítica e estudo. 2 vols. Lisboa: INIC, 1989.

110. CHAGAS, C. H. O papel social da língua: o poder das variedades linguísticas. Disponível em:

http://www.filologia.org.br/viiicnlf/anais/caderno10-

07.html. Acesso em: 10-09-2010.

111. CHEDIAK, A. J. A correlação em Vieira. Revista Filológica 7 (25), 1944, Rio de Janeiro, 1944.

112. . A nomenclatura gramatical brasileira e sua elaboração. Rio de Janeiro: MEC/CADES, 1960.

113. __ Aspectos da estrutura correlativa em Camões. Rio de Janeiro. Tese de concurso para uma das cadeiras de português do Colégio Pedro II, 1963.

114. __ Contribuição ao estudo da estrutura correlativa em Camões. Rio de Janeiro: UFRJ, tese de doutoramento, 1971.

115. CINTRA, L. F. L. A linguagem dos foros de Castelo Rodrigo: seu confronto com a dos foros de Alfaiates, Castelo Bom, Castelo Melhor, Coria, Cáceres, Usagre. Contribuição para o estudo do leonês antigo e do galego-português do séc. XIII. Lisboa: C.E.F., 1959.

116. __ Crónica geral de Espanha de 1344. Edição crítica do texto português. 3 vols. Lisboa: Academia Portuguesa da Histó- 
ria [Reprodução fac-similada, Lisboa, IN-CM, 1983 (vol.I), 1984 (vols. II - IV)].

117. _ Dois textos não literários transmontanos do século XIII (leitura crítica e comentário linguístico). Boletim de Filologia 33, 2006.

118. Costa, 1983.

119. . Langue parlée et traditions écrites au Moyen Âge (Péninsule Ibérique). In: Atti XIV Congresso Internazionale di Linguistica e Filologia Romanza (Napoli 1974), Vol. I, Napoli: Gaetano Macchiaroli; Amsterdam: John Benjamins, 1998, p. 463-472

120. __ Les anciens textes portugais non littéraires. Classement et bibliographie. In: FARIA, I. H. (Org.). Lindley Cintra. Homenagem ao Homem, ao Mestre e ao Cidadão. Lisboa: Cosmos / FLL, 1999, p. 199-215.

121. . Observations sur l'ortographe et la langue de quelques textes non littéraires galiciens-portugais de la seconde moitié du XIIIe siècle. In: FARIA, I. H. (Org.). Lindley Cintra. Homenagem ao Homem, ao Mestre e ao Cidadão. Lisboa: Cosmos / FLL, 1999, p. 216-231.

122. ___ Observations sur le plus ancien texte portugais non littéraire: la 'Noticia de Torto' (lecture critique, date et lieu de rédaction). In: Actele celui de-al XII Congres International de Lingvistica si Filologie Romanica (Bucuresti 1968), Vol. II. Bucuresti, 1971, p. 161-174.

123. Sobre o mais antigo texto não literário português: A Notícia de Torto (leitura crítica, data, lugar de redação e comentário linguístico). Boletim de Filologia 31, 1986-1987, p. 21-77.

124. __ Situação actual da língua portuguesa no mundo. In: FARIA, I. H. (Org.). Lindley Cintra. Homenagem ao homem, ao mestre e ao cidadão. Lisboa: Cosmos / FLL, 1999, p. 289300 . 
125. . (reprod. fac-sim.). A linguagem dos foros de Castelo Rodrigo. Seu confronto com a dos foros de Alfaiates, Castelo Bom, Castelo Melhor, Coria, Cáceres e Usagre - contribuição para o estudo do leonês e de galego-português do século XIII. Lisboa: Imprensa Nacional-Casa da Moeda, 1984.

126. CLARE, N. A. V. Metodologia do ensino de história da língua portuguesa. Disponível em:

http://www.filologia.org.br/xiicnlf/textos_completos/Metodo logi-

a\%20do\% 20ensino\% 20de\% 20Hist\% C3\%B3ria\% 20da\%2 0L\% C3\% ADngua \% 20Portuguesa \% 20\%20N\% C3\%8DCIA.pdf. Acesso em: 10-09-2010.

127.

Disponível em: 50 anos de ensino de língua portuguesa (1950-2000).

http://www.filologia.org.br/vcnlf/anais\% 20v/civ6_01.htm. Acesso em: 10-09-2010.

128. __ As mudanças linguísticas: ontem/hoje. Disponível em: http://www.filologia.org.br/viiicnlf/anais/caderno1007.html. Acesso em: 10-09-2010.

129. COELHO, I. L.; MONNGUILLOTT, I. O. S.; MARTINS, M. A. Estudo diacrônico da inversão verbo-sujeito no PB: fenômenos correlacionados. In: RONCARATI; ABRAÇADO (Orgs., 2008, p. 137-157).

130. COHEN, M. A. A. M.; RAMOS, J. (Orgs.). O dialeto mineiro e outras falas. Belo Horizonte: Faculdade de Letras da UFMG, 2002.

131. CORPUS Codicum Latinorum et Portucalensium eorum qui in Archivo Municipali portucalensi asservantur antiquissimorum. II. Porto, 1917.

132. CORREDOIRA, F. V. A construção da língua portuguesa frente ao castelhano: o galego como exemplo a contrário. Compostela: Laiovento, 1998.

133. COSERIU, E. Sincronia, diacronia e história. O problema de mudança linguística. Rio de Janeiro: Presença, 1979. 
134. COSTA, A. J. Os mais antigos documentos escritos em português: revisão de um problema histórico-linguístico. Revista Portuguesa de História 17, 1979, p. 263-340.

135. . Os mais antigos documentos escritos em português. Revisão de um problema histórico-linguístico. In: Estudos de Cronologia, Diplomática, Paleografia e Histórico-Linguísticos. Porto: Sociedade Portuguesa de Estudos Medievais, 1992, p. 169-256.

136. COSTA, S. B.; MACHADO FILHO, A. V. L. (Orgs.). Do português arcaico ao português brasileiro. Salvador: UFBA, 2004.

137. COUTINHO, I. L. Gramática histórica. Rio de Janeiro: Acadêmica, 1973. [Inicialmente editado com o título Pontos de gramática histórica].

138. CRUZ, L. S. Aspectos fonéticos do barlavento do Algarve: as vogais finais acentuadas. In: DUARTE, I.; LEIRIA, I. (Eds.). Actas do Congresso Internacional sobre o Português (Lisboa, 1994), Vol. II. Lisboa: Colibri, 1996, p. 345-358.

139. ___ SARAMAGO, J. Açores e Madeira: autonomia e coesão dialectais. In: FAROA, I. H. (org.) Lindley Cintra. Homenagem ao homem, ao mestre e ao cidadão. Lisboa: Cosmos, FLL, 1999, p. 707-738.

140. CRUZEIRO, M. E. Processos de intensificação no português dos sécs. XIII a XV. Lisboa: C. E. F., 1974.

141. CUNHA, A. G. Dicionário etimológico Nova Fronteira. Rio de Janeiro: Nova Fronteira, 1982.

142. __ Dicionário histórico das palavras portuguesas de origem tupi. São Paulo: Melhoramentos, 1989.

143. ___ Vocabulário histórico-cronológico do português medieval. Rio de Janeiro: Casa de Rui Barbosa, 1986 e 1988, 2 t. [Também em cd-rom, s/d.]

144. CUNHA, C. F. A questão da norma culta brasileira. Rio de Janeiro: Tempo Brasileiro, 1985. 
145 . . Cancioneiros dos trovadores do mar. Edição preparada por Elsa Gonçalves. Lisboa: Imprensa Nacional-Casa da Moeda, 1999.

146. . Estudos da poética trovadoresca: versificação e ecdótica. Rio de Janeiro: Instituto Nacional do Livro, 1961.

147. . Língua portuguesa e realidade brasileira. 2. ed. Rio de Janeiro: Tempo Brasileiro, 1970.

148. . Uma política do idioma. Rio de Janeiro: São José, 1964.

149. CYRINO, S. M. L. O objeto nulo no português do Brasil: um estudo sintático-diacrônico. Londrina: UEL, 1997.

150. __ Observações sobre a mudança diacrônica no português do Brasil: objecto nulo e clíticos. In: ROBERTS; KATO (Eds., 1996, p.163-184).

151. __ _ Uma proposta para o estudo da sintaxe diacrônica do português brasileiro. In: CASTILHO (Org., 1998, p. 89-100).

152. DECAT, M. B. N. Construções de tópico em português: uma abordagem diacrônica à luz do encaixamento no sistema pronominal. In: TARALLO (Org., 1989, p. 113-139).

153. DIAS, A. E. S. Syntaxe historica portuguesa. 3. ed. Lisboa: Clássica, 1954.

154. DIETRICH, W. Bibliografia da língua portuguesa do Brasil. Tubingen: Narr, 1980.

155. ___ NOLL, V. (Orgs.). O português do Brasil: perspectivas da pesquisa atual. Frankfurt am Main: Vervuert; Madrid: Iberoamericana, 2004.

156. DOCKHORN, N. A necessidade de usar transcrições fonéticas no estudo da variedade popular do latim. Disponível em: http://www.filologia.org.br/viiicnlf/anais/caderno1002.html. Acesso em: 10-09-2010.

157. DUARTE, I.; GONÇALVES, A.; MIGUEL, M.; MOTA, M. A. "Não cheguei de aprender nada". Áreas de variação e tendências de mudança no português de Moçambique. In: LOPES, A. 
C.; MARTINS, M. C. (Eds.). Actas do XIV Encontro Nacional da Associação Portuguesa de Linguística (Aveiro 1998). Vol. I. Braga: Gráfica de Coimbra, 1999, p. 477-493.

158. DUARTE, L. F. (Ed.). Os documentos em português da Chancelaria de D. Afonso III. Diss. de Mestrado. Universidade de Lisboa, Faculdade de Letras, 1986.

159. ___. Uma scripta em construção (A constituição de uma norma escrita do galego-português no século XIII). In: Actas do I Congresso da Língua Galego-Portuguesa na Galiza. A Coruña, AGAL, 1986, p. 663-674.

160. DUARTE, L. P. (Org.). Para sempre em mim: homenagem à professora Ângela Vaz Leão. Belo Horizonte: PUC-MG, 1999.

161. DUARTE, M. E. L. Do pronome nulo ao pronome pleno: a trajectória do português do Brasil. In: ROBERTS; KATO (Eds., 1996, p. 107-128).

162. __ CALLOU, D. M. I. (Orgs.). Para a história do português brasileiro. V. IV - notícias de corpora e outros estudos. Rio de Janeiro: UFRJ-Letras, 2002.

163. DUARTE, P. M. T. A formação de palavras por prefixo em português. Fortaleza: UFC, 1999.

164. ELIA, S. Fundamentos histórico-linguísticos do português do Brasil. Rio de Janeiro: Lucerna, 2003.

165. __ O problema da língua brasileira. Rio de Janeiro: Pongetti, 1940.

166. __ Um século de separação ortográfica. In: HAYE (Org., 1995, p. 305-312).

167. EMILIANO, A. O mais antigo documento latino-português (882 a.D.) - edição e estudo grafêmico". Verba 26, 1999, p. 742.

168. Sobre a questão d'“'os mais antigos textos escritos em português". In: CASTRO, I.; DUARTE, I. (Eds.). Razões $e$ Emoção, Miscelânea de estudos em homenagem a Maria Hele- 
na Mira Mateus. Vol. I, Lisboa: Imprensa Nacional-Casa da Moeda, 2003, p. 261-278.

169. ; PEDRO, S. De noticia de torto: aspectos paleográficos e scriptográficos e edição do mais antigo documento particular português conhecido. Zeitschrift für romanische Philologie 120/1, 2004, p. 1-81.

170. FARACO, A. C. Linguística histórica: uma introdução ao estudo da história das línguas. São Paulo: Ática, 1988.

171. FARIA, E. Fonética histórica do latim. Rio de Janeiro: Acadêmica, 1970.

172. FÁVERO, L. L.; MOLINA, M. A. G. A gramática lusobrasileira e o método científico. Filologia e Linguística Portuguesa 9. São Paulo: USP/FFLCH, 2007, p. 27-42.

173. FEIJÓ, J. M. M. Orthographia ou Arte de Escrever, e Pronunciar com acerto a Lingua Portuguesa. Segunda impressão. Coimbra: Luis Secco Ferreira, 1739.

174. FERNANDES, A. P. A história da ortografia do português do Brasil. Disponível em:

http://www.filologia.org.br/venlf/anais\% 20v/civ6_01.htm.

Acesso em: 10-09-2010.

175. FERNÁNDEZ REI, F. Posición do Galego entre as linguas románicas. Verba 15, 1988, p.79-107.

176. FERREIRA, J. A. Afonso X. Foro Real. Edição, estudo linguístico e glossário. Lisboa: INIC, 1987, 2 v.

177. . Alphonse X. "Primeyra Partida". Edition et étude. Braga: INIC, 1980.

178. . Edição e estudo linguístico dos "Tempos dos Preitos". In: ROUDI, J. Jacobo de Junta. Summa de los Nueve Tiempos de los Pleitos. Édition et étude d'une variation sur un thème. Paris: Publ. du Séminaire d'Etudes Médiévales Hispaniques de l'Université Paris 13, 1986, p. 151-169.

179. Estudos de história da língua portuguesa: Obra dispersa. Organizada por Brian F. Head, Maria Aldina Marques e Ai- 
da Sampaio. [Minho]: Universidade do Minho / Centro de Estudos Humanísticos, 2001.

180. Flores de Dereyto. Braga, 1989.

181. FERREIRO, M. Gramática histórica galega. Santiago de Compostela: Laiovento, 1995.

182. FERREIRA, M. B. Vestígios do romance moçarábico em Portugal. Revista de Arqueologia Medieval 1. Mértola, 1992, p. 217-228.

183.

CARRILHO, E.; LOBO, M.; SARAMAGO, J.;

CRUZ, L. S. Variação linguística: perspectiva dialectológica. In: FARIA, I. H. et al. (Eds.). Introdução à Linguística Geral e Portuguesa. Lisboa: Caminho, 1996, p. 477-502.

184. FONSECA, F. V. P. da. Noções de história da língua portuguesa. Lisboa: Clássica, 1959.

185. . O português entre as línguas do mundo: situação, história, variedades. Coimbra: Almedina, 1985.

186. FERRO COUSELO, X. A vida e a fala dos devanceiros. Tomo I. Terras de Ourense, Vol. II. Vigo: Galaxia, 1967.

187. FREITAS, H. R. A obra de Olmar Guterres da Silveira: sua contribuição aos estudos das línguas portuguesa e latina. Rio de Janeiro: H. Rolim de Freitas, 1996.

188. GALVES, C. C. O enfraquecimento da concordância no português brasileiro. In: ROBERTS; KATO (Eds., 1996, p. 387408).

189. GÂNDAVO, P. M. Regras que ensinam a maneira de escrever a orthographia da lingua portugueza. Lisboa: Antonio Gonsalvez, 1574.

190. GARCIA, A. S. História da ortografia do português do Brasil. Rio de Janeiro: UFRJ, 1996.

191. O português do Brasil: questões de substrato, superstrato e adstrato. Disponível em:

http://www.filologia.org.br/soletras/4/07.htm. Acesso em: 10-09-2010. 
192. GÄRTNER, E. O papel dos falantes afro-brasileiros na formação do diassistema do português brasileiro. In: SCHRADERKNIFFKI; GARCÍA (Eds., 2007, p. 365-389).

193. Tentativa de explicação diacrônica de alguns fenômenos morfossintáticos do português brasileiro. In: ALKMIM (Org., 2002, p. 293-328).

194. . Em torno da origem do emprego de pronomes pessoais sujeito em função de objeto direto no português brasileiro: considerações metodológicas. In: KOLLER et alii (Eds.). Ciências da linguagem: 30 anos de investigação e ensino. Braga: Universidade do Minho, 2005, p. 85-98.

195. HUNDT, C.; SCHÖNBERGER, A. (Eds.). Estudos de sociolinguística brasileira e portuguesa. Grankfurt am Main: TFM, 2000.

196. . (Eds.). Estudos geolinguísticos do português americano. Grankfurt am Main: TFM, 2000.

197. et alii (Eds.). Estudos de história da língua portuguesa. Frankfurt am Main: TFM, 1999.

198. GARVÃO, H. Foros de Garvão. Dissertação de Mestrado. Lisboa: Universidade de Lisboa, Faculdade de Letras, 1990.

199. GÓIS, M. V. S. A influência do estrangeirismo na língua portuguesa: um processo de globalização ideologia e comunicação. Disponível em:

http://www.filologia.org.br/revista/40/A\% 20INFLU\%C3\% 8ANCIA\% 20DOS\% 20ESTRANGEIRISMOS.pdf. Acesso em: 10-09-2010.

200. GONÇALVES, M. F. Madureira Feijó, ortografista do século XVIII. Para uma História da Ortografia Portuguesa. Lisboa: ICALP, 1992.

201. . As ideias ortográficas em Portugal de Madureira Feijó a Gonçalves Viana (1734-1911). Lisboa: Fundação Calouste Gulbenkian / FCT, 2003. 
202. GONÇALVES, P. Aspectos da sintaxe do português de Moçambique. In: FARIA, I. H. et al. (Eds.), Introdução à Linguística Geral e Portuguesa. Lisboa: Caminho, 1996, p. 313-322.

203. . Situação actual da língua portuguesa em Moçambique. In: CINTRA, L. F. L. et al. (Eds.). Actas do Congresso sobre a situação actual da língua portuguesa no mundo (Lisboa 1983), Vol. I. Lisboa: ICALP, 1985, p. 243-252.

204. GONÇALVES, U. S.; FERREIRA, P. S. Aventura no reino das traças: contribuindo para uma história linguística da Bahia. In: MATTOS E SILVA (Org., 2001, t. 2, p. 483-504).

205. GROSSE, S.; ZIMMERMANN, K. (Orgs.). "Substandard” $e$ mudança no português do Brasil. Frankfurt am Main: TFM, 1998.

206. GROSSO, M. J. O português em Macau: diálogo de culturas. In: DUARTE, I; LEIRIA, I. (Eds.). Actas do Congresso Internacional sobre o Português (Lisboa 1994), Vol. III. Lisboa: Colibri, 1996, p. 207-213.

207. GUEDES, M.; BERLINCK, R. A. Fontes para a história da língua portuguesa no "Velho Oeste Paulista". In: MATTOS E SILVA (Org., 2001, t. 2, p. 443-482).

208. HNRIQUES, M. A. Situação e perspectivas do português na Guiné-Bissau. In: CINTRA, L. F. L. et alii. (Eds.). Actas do Congresso sobre a situação actual da língua portuguesa no mundo (Lisboa 1983), Vol. I. Lisboa: ICALP, 1985, p. 235242.

209. HERNÁNDEZ, A. G. Temas de linguística política: seguidos dum avanço de temas de política; leves reflexões sobre política nacional "española". Santiago de Compostela: Acrunha/Associação de Amizade Galiza-Portugal, 2005

210. HEYE, J. (Org.). Flores verbais: uma homenagem linguística e literária para Eneida do Rego Monteiro Bomfim no seu $70^{\circ}$ aniversário. 1. ed. Rio de Janeiro: Ed. 34, 1995. 
211. HISTÓRIA da língua portuguesa. Disponível em: http://pt.wikipedia.org/wiki/Hist\%C3\%B3ria_da_1\%C3\%ADng ua portuguesa. Acesso em: 26-09-2010.

212. HISTÓRIA da língua portuguesa. Vídeos disponíveis em:

http://www.youtube.com/results?search_query $=\% 22 \mathrm{Hist} \%$ C3\%B3ria+da+L\% C3\% ADngua+Portuguesa \% 22\&aq=f. Acesso em: 10-09-2010.

213. HÜBNER, J. Gramática do português arcaico. Lisboa: Gulbenkian, 1986.

214. KATO, M. A. O português brasileiro falado: aquisição em contexto de mudança linguística. In: DUARTE, I.; LEIRIA, I. (Eds.). Actas do Congresso Internacional sobre o Português (Lisboa 1994), Vol. II. Lisboa: Colibri, 1996, p. 209-237.

215 . Português brasileiro no fim do século XIX e na virada do milênio. In: CARDOSO; MOTA; MATTOS E SILVA (Orgs., 2006, p. 413-438).

216. __ Recontando a história das relativas em uma perspectiva paramétrica. In: ROBERTS; KATO (Eds.), 1996, p. 223306.

217. ; ROBERTS, I. (Orgs.). Português brasileiro: uma viagem diacrônica. Campinas: UNICAMP, 1993.

218. KEMMLER, R.; SCHÄFER-FRIESS, B.; SCHÖNBERGER, A. (Eds.). História da gramaticografia e lexicografia portuguesas. Frankfurt am Main: DEE, 2002.

219. KEWTTZ, V. A gramaticalização da preposição "entre" no português brasileiro do séc. XIX. In: RAMOS; ALKMIN (Orgs., 2007, p. 169-180).

220. . Gramaticalização de "ser" e "estar" no português medieval e no séc. XIX. Dissertação de mestrado. São Paulo: USP, 2002.

221. . Gramaticalização e semanticização das preposições "a" e "para" no português brasileiro (séc. XIX a XX). Tese de doutorado. São Paulo: USP, 2007. 
222. - Gramaticalização, semanticização e discursivização das preposições "a" e "para" no português brasileiro (sécs. XIX e XX). In: CASTILHO (Orgs., 2009, p. 603-736).

223. . Os verbos "ser" e "estar" plenos no português arcaico. Estudos Linguísticos 31, 2002, cd-rom.

224. ; OLIVEIRA, M. A representação do caipira na imprensa paulista do séc. XIX. In: DUARTE; CALLOU (Orgs., 2002, p. 27-35).

225. ; SIMÕES, J. S. Normas linguísticas, história social, contatos linguísticos e tradições discursivas: transformando encruzilhadas em novos caminhos para a constituição de corpora diacrônicos. In: CASTILHO (Org., 2009, p. 699-720).

226. KREMER, D. (Ed.). Homenagem a Joseph M. Piel por ocasição do seu $85^{\circ}$ aniversário. Tübingen: Max Niemeyer Verlag/Instituto de Cultura e Língua Portuguesa/Conselho da Cultura Galega, 1988.

227. 19, 1992, p. 7-18.

228. LANCIANI, G.; TAVANI, G. (Orgs.). Dicionário da Literatura Medieval Galega e Portuguesa. Lisboa: Caminho, 1993.

229. LAPA, M. R. Miscelânea de língua e literatura portuguesa medieval. Rio de Janeiro: INL, 1965.

230. LAPESA, R. Historia de la lengua española. 7. ed. Madrid: Escelicer, 1968.

231. LAYTANO, D. O português de Açores na consolidação moral do domínio luso no extremo sul do Brasil. Congresso do Mundo Português. Lisboa, 1940, vol. XI, t. 2, p. 341-356.

232. LEÃO, A. V. Estruturas de negação reforçada nas Cantigas de Santa Maria. In: CAVALIERE (Org., 2008, p. 75-88).

233. LEÃO, D. N. de. Ortografia e origem da língua portuguesa. Introd. notas e leitura Maria Leonor Carvalhão Buescu. Lisboa: Imprensa Nacional/Casa da Moeda, 1983. 
234. LESSA, L. C. O modernismo brasileiro e a língua portuguesa. Rio de Janeiro: Fundação Getúlio Vargas, 1966.

235. LIMA, O. M. G. Breve história do português do Brasil. Disponível em:

http://www.filologia.org.br/linguagememrevista/01/04.htm. Acesso em: 10-09-2010.

236. LIMA SOBRINHO, A. B. A língua portuguesa e a unidade do Brasil. Rio de Janeiro: J. Olympio, 1958.

237. LÍNGUA galego-portuguesa. Disponível em: http://pt.wikipedia.org/wiki/L\%C3\%ADngua galegoportuguesa. Acesso em 26-09-2010.

238. LLEAL, C. La formación de las lenguas romances peninsulares. Barcelona: Barcanova, 1990.

239. LOBO, T. A questão da periodização na história linguística do Brasil. In: CASTRO, I.; DUARTE, I. (Eds.). Razões e emoção, miscelânea de estudos em homenagem a Maria Helena Mira Mateus. Vol. I. Lisboa: Imprensa Nacional-Casa da Moeda, 2003, p. 395-409.

240. LOBO, T. C. F. A colocação dos clíticos em português: duas sincronias em confronto. Dissertação de mestrado. Lisboa: Universidade de Lisboa, 1992.

241. __ Para uma sociolinguística histórica do português no Brasil: edição filológica e análise linguística de cartas particulares do Recôncavo da Bahia, século XIX. São Paulo: USP, 2001.

242. ; OLIVEIRA, K. História social linguística do Brasil no âmbito do Projeto para a História do Português Brasileiro. In: CASTILHO (Org., 2003, p. 68-112).

243. .et alii. Para a história do português brasileiro: V. VI novos dados, novas análises. Salvador: UFBA, 2006, 2 t.

244. LONGHIN-THOMAZI, S. R. A gramaticalização da perífrase conjuncional "só que". Tese de doutorado. Campinas: UNICAMP, 2003. 
245. LOPES, C. R. S. A inserção de "a gente" no quadro pronominal do português: percurso histórico. Frankfurt am Main: Vervuert; Madrid: Iberoamericana, 1999/2002.

246. . A norma brasileira em construção: fatos linguísticos em cartas pessoais do século 19. Rio de Janeiro: UFRJ, 2005.

247. . Correlações histórico-sociais e linguístico-discursivas das formas de tratamento em textos escritos no Brasil - séculos XVIII e XIX. In: Guiomar Ciapuscio; Konstanze Jungbluth, Dorothee Kaiser; Célia Lopes. (Org.). Sincronia y diacronia: de tradiciones discursivas en Latinoamérica. Frankfurt: Vervuert/Bibliotheca Ibero-Americana, 2006, v. 107. ISBN: 8484892719. Disponível em: http://www.letras.ufrj.br/laborhistorico/12-lopes.pdf. Acesso em: 20-09-2010.

248. __ Gramaticalização de conjunções coordenativas: a história de uma conclusiva. Gragoatá 21, 2006.

249. . Laboratório de História do Português Brasileiro: Universidade Federal do Rio de Janeiro. Disponível em: http://www.letras.ufrj.br/laborhistorico. Acesso em: 20-092010.

250.

DELTA - Revista de Documentação de Estudos em Linguística Teórica e Aplicada, São Paulo, v. 14, n. 2, p. 405-422, 1998. Disponível em: http://www.scielo.br/scielo.php?pid=S010244501998000200006\&script=sci_arttext. Acesso em 20-092010.

251. O percurso de "a gente" em tempo real de longa duração. In: MATTOS E SILVA (Org., 2001, t. I, p. 127-148).

252. . Retratos da variação entre "você" e "tu" no português do Brasil: sincronia e diacronia. In: RONCARATI; ABRAÇADO (Orgs., 2008, p. 55-71).

253. . Vossa mercê > você e Vuestra merced > usted: o percurso evolutivo ibérico. Revista de Linguística da ALFAL, São Paulo, v. 14, p. 173-190, 2004. Disponível em: 
http://www.letras.ufrj.br/laborhistorico/ALFAL.pdf. Acesso em: 20-09-2010.

254. ; DUARTE, M. E. L. De Vossa Mercê a Você: análise da pronominalização de nominais em peças brasileiras e portuguesas setecentistas e oitocentistas. In: BRANDÃO, Silvia Figueiredo; MOTA, Maria Antónia. (Org.). Análise contrastiva de variedades do português: primeiros estudos. I ed. Rio de Janeiro: In-Fólio, 2003, v. I, p. 61-76. Disponível em:

http://www.letras.ufrj.br/laborhistorico/pe\%E7as.pdf. Acesso em: 20-09-2010.

255. LOPES, E. A identidade e a diferença: raízes históricas das teorias estruturais da narrativa. São Paulo: USP, 1997.

256. LOPES ROSSI, M. A. Estudo diacrônico sobre as interrogativas do português do Brasil. In: ROBERTS; KATO (Orgs., 1993, p. 307-342).

257. . As orações interrogativas- $Q$ no português do Brasil: um estudo diacrônico. Tese de doutorado. Campinas: UNICAMP, 1996.

258. LOPEZ, D. Textos em aljamia portuguesa. Lisboa: Imprensa Nacional, 1897.

259. LORENZINO, G. A. Uma avaliação sociolinguística sobre São Tomé e Príncipe. In: DUARTE, I.; LEIRIA, I. (Eds.). Actas do Congresso Internacional sobre o Português (Lisboa 1994), Vol. III. Lisboa: Colibri, 1996, p. 435-451

260. LORENZO, R. A situación actual do galego. In: DUARTE, I.; LEIRIA, I. (Eds.). Actas do Congresso Internacional sobre o Português (Lisboa, 1994), Vol. I. Lisboa: Colibri, 1996, p. 283309.

261. Algunhas consiceracións sobre a evolución do vocalismo en galego e português. Actas do VIII Encontro da Associação Portuguesa de Linguística. Lisboa: Associação Portuguesa de Linguística, 1993, p. 9-26. 
262. Algúns datos sobre a evolución das sibilantes medievais. In: PEREIRA; PEREIRA (Orgs. e Coords., 1995, p. 231237).

263. .Consideracións sobre as vocais nasais e o ditongo - ão en português. In: KREMER (Ed., 1988, p. 289-326).

264. . Crónica Troiana. A Coruña: Fundación Pedro Barrié de la Maza, Conde de Fenosa, 1985.

265. La traducción gallega de la Crónica General y de la Crónica de Castilla. Edición crítica anotada con introduccíon, índice onomástico y glosario. Orense: Instituto de Estudios Orensanos "Padre Feijoo", 1975 e 1977, 2 v.

266. LUCCHESI, D. A constituição histórica do português brasileiro como um processo bipolarizador: tendências atuais de mudança nas normas culta e popular. In: GROSSE; ZIMMERMANN (Eds., 1998, p. 73-100).

267. _ As duas grandes vertentes da história sociolinguística do Brasil (1500-2000). DELTA 17 (1), 2001m p. 97-130.

268. ___ _ LOBO, T. Aspectos da sintaxe do português brasileiro. In: FARIA, I. H. et al. (Eds.). Introdução à Linguística Geral e Portuguesa. Lisboa: Caminho, 1996, p. 303-311.

269. LÜDTKE, H. Fonemática portuguesa I: consonantismo. Boletim de Filologia XIII, 1952, p. 273-288.

270. . Fonemática portuguesa II: vocalismo. Boletim de Filologia XIV, 1953, p. 197-217.

271. Historia del léxico románico. Trad. Marcos Martínez Hernández. Madrid: Gredos, [s/d.].

272. LUZ-FREITAS, M. S. E a língua portuguesa se tornou disciplina curricular. Disponível em:

http://www.filologia.org.br/revista/33/04.htm. Acesso em: 10-09-2010.

273. MACÊDO, A. M. N. Locuções prepositivas na constituição histórica da língua portuguesa. Dissertação de mestrado. Salvador: UFBA, 1997. 
274. Gramaticalização de locuções prepositivas na história do galego e do português. Tese de doutorado. Salvador: UFBA, 2003, 3 v.

275. MACHADO, J. P. Dicionário etimológico da língua portuguesa. Lisboa: Confluência/Livros Horizonte, 1977, 2 vols.

276. Álvaro Pinto, 1952.

277. . Origens do português: ensaio. 2. ed. rev. Lisboa, 1967.

278. . Ensaios arábico-portugueses. Lisboa: Notícias, 1997.

279. MACHADO, M. S. Estudo diacrônico e sincrônico da ortografia do português do Brasil: uma odisseia linguística. Disponível em: http://www.filologia.org.br/cluerjsg/anais/iii/completos\% 5Cmesas\% 5CM\% 202\%5CMarcos \%20da\% 20Silva\% 20Machado.pdf. Acesso em: 10-09-2010.

280. MAIA, C. de A. Dos textos escritos à história da língua. História da Língua e História da Gramática. Atas do Encontro. Braga: Universidade do Minho, 2002, p. 231-249.

281.

A abordagem dos textos medievais (Reflexões sobre alguns fragmentos das Partidas de Afonso X). In: CASTRO, I. (Ed.). Actas do XII Encontro Nacional da Associação Portuguesa de Linguística (Braga / Guimarães 1996) Vol. II. Lisboa, 1997, p. 157-169.

282. . Dos textos escritos à história da língua. In: HEAD, B. F. et al. (Eds.). História da Língua e História da Gramática: Actas do Encontro. Braga: Universidade do Minho, 2002, p. 231-249.

283. . Geografia dialectal e história do português: resultados da terminação latina -ana. Biblos 57, 1981, p. 73-96.

284. . História da língua portuguesa: guia de estudo. Coimbra: Faculdade de Letras da Universidade de Coimbra, 1995. 285. . História do galego-português. Estado linguístico da Galiza e do Noroeste de Portugal do século XIII ao século XVI 
(Com referência à situação do galego moderno). Coimbra, INIC, 1986.

286. - História do galego-português: estado linguístico da Galiza e do noroeste de Portugal desde o século XIII ao século XVI. Coimbra: Instituto Nacional de Investigação Científica, 1986.

287. O galego visto pelos filólogos e linguistas portugueses. Cadernos da Cátedra de Estudos Galegos 3. Lisboa: Cátedra de Estudos Galegos da Universidade de Lisboa / Colibri, 2002.

288.

O galego-português medieval: sua especificidade no contexto dos romances peninsulares e futura diferenciação do galego e do português. In: DUARTE, I.; LEIRIA, I. (eds.). Actas do Congresso Internacional sobre o Português (Lisboa 1994). Vol. I. Lisboa: Colibri, 1996, p. 33-51

289.

O Tratado de Tordesilhas: algumas observações sobre o estado da língua portuguesa em finais do séc. XV. Biblos 70 , 1994, p. 33-91.

290. . O tratamento das variedades do português nos gramáticos e ortografistas de Setecentos: especial referência a Monte Carmelo. In: THIELEMANN, W. (Ed.) Século XVIII: século das luzes, século de Pombal. Frankfurt am Main: TFM, 2001, p. 33-50.

291.

Os falares do Algarve (inovação e conservação). Separata da Revista Portuguesa de Filologia 17 (Tomos I e II), 1978 , p. $37-205$

292. Periodização na história da língua portuguesa: status quaestionis e perspectivas de investigação futura. In: GÄRTNER et alii. (Eds., 1999, p. 21-39).

293. Sociolinguística histórica e periodização linguística. Algumas reflexões sobre a diferença entre português arcaico e português moderno. Diacrítica 10, Braga, 1995, p. 3-30.

294. MARIANI, B. Colonização linguística: línguas, política e religião no Brasil (séculos XVI a XVIII) e nos Estados Unidos da América (séulo XVIII). Campinas: Pontes, 2004. 
295. MARIÑO PAZ, R. Historia da lingua galega. Compostela: Sotelo Blanco, 1999.

296. MARQUES, A. H. O. (dir.). Chancelarias portuguesas - D. Pedro I. Lisboa: INIC, 1984.

297. Chancelarias portuguesas - D. Afonso IV. Lisboa: INIC, 1990 e 1992, 3 v.

298. MARQUES, I. G. Algumas considerações sobre a problemática linguística em Angola. In: CINTRA, L. F. L. et alii. (Eds.). Actas do Congresso sobre a situação actual da língua portuguesa no mundo (Lisboa 1983), Vol. I. Lisboa: ICALP, 1985, p. 205224.

299. MARQUILHAS, R. Norma gráfica setecentista. Do autógrafo ao impresso. Lisboa: INIC, 1991.

300. Níveis de alfabetização no Portugal de seiscentos. In: CASTRO, I. (ed.). Actas do XII Encontro Nacional da Associação Portuguesa de Linguística (Braga / Guimarães 1996). Vol. II. Lisboa: Colibri, 1997, p.171-178.

301. A Faculdade das Letras. Leitura e escrita em Portugal no século XVII. Lisboa: Imprensa Nacional-Casa da Moeda, 2000.

302. Mudança analógica e elevação das vogais pretónicas. In: CASTRO, I.; DUARTE, I. (Eds.). Razões e emoção. Miscelânea de estudos em homenagem a Maria Helena Mira Mateus. Vol. II, Lisboa: Imprensa Nacional-Casa da Moeda, 2003, p. 718

303. MARTELOTTA, M. E.; BARBOSA, A.; LEITÃO, M. M. Ordenação de advérbios intensificadores e qualitativos em -mente em cartas de jornais do séc. XIX: bases para uma análise diacrônica. In: DUARTE; CALLOU (Orgs., 2002, p. 167-176).

304. MARTÍNEZ SALAZAR, A. Documentos gallegos de los siglos XIII a XVI. Corunha: Imprenta de la Casa de la Misericordia, 1911.

305. MARTINS, A. M. A emergência do português escrito na segunda metade do século XII. In: ALVAREZ BLANCO, R.; 
SANTAMARINA, A. (Eds.). Homenagem a Fernando Tato Plaza. Santiago de Compostela: Instituto da Língua Galega, 2006.

306. . A evolução das vogais nasais finais $\tilde{a}, \tilde{o}$, no português. In: PEREIRA, C. C.; PEREIRA, P. R. D. (Eds.). Miscelânea de Estudos Linguísticos, Filológicos e Literários in Memoriam Celso Cunha. Rio de Janeiro: Nova Fronteira, 1995, p. 617646.

307. Ainda "os mais antigos textos escritos em português". Documentos de 1175 a 1252 . In: FARIA, I. H. (org.), Lindley Cintra. Homenagem ao Homem, ao Mestre e ao Cidadão. Lisboa: Cosmos / FLL, 1999, p. 491-534.

308. Aspectos da negação na história das línguas românicas (da natureza de palavras como nenhum, nada, ninguém). In: CASTRO, I. (Ed.) Actas do XII Encontro Nacional da Associação Portuguesa de Linguística (Braga / Guimarães 1996). Vol. II. Lisboa: Colibri, 1997, p. 179-210

309. Clíticos na história do português. Lisboa: Universidade de Lisboa, 1994.

310. Construções com se: mudança e variação no português europeu. In: CASTRO, I.; DUARTE, I. (Eds.). Razões e Emoção, Miscelânea de estudos em homenagem a Maria Helena Mira Mateus. Vol. II. Lisboa: Imprensa Nacional-Casa da Moeda, 2003, p. 19-41.

311. Documentos portugueses do Noroeste e da Região de Lisboa: da produção primitiva ao século XVI. Lisboa: Imprensa Nacional-Casa da Moeda, 2001.

312. Elementos para um comentário linguístico do Testamento de D. Afonso II (1214). Faculdade de Letras da Universidade de Lisboa (trabalho de síntese apr. a Provas de Aptidão Pedagógica e Capacidade Científica), 1985.

313. Emergência e generalização do português escrito: de D. Afonso Henriques a D. Dinis. In: MATEUS, M. H. (ed.) Caminhos do Português: Exposição Comemorativa do Ano Eu- 
ropeu das Línguas (Catálogo). Lisboa: Biblioteca Nacional, 2001, p. 23-71.

314. . Gramáticas históricas do português. In DUARTE, I.; MATILDE, M. (Eds.). Actas do XI Encontro da Associação Portuguesa de Linguística (Lisboa 1995), Vol. III, 1996, p. 5371.

315. . Mudança sintáctica e história da língua portuguesa. In: HEAD, B. F. et alii. (Eds.). História da língua e história da gramática: Actas do Encontro. Braga: Universidade do Minho, 2002, p. 251-297.

316. ___ ALBINO, C. Sobre a primitiva produção documental em português: notícia de uma noticia de auer. In: KREMER, D. (ed.), Homenaxe a Ramón Lorenzo. Vol. I, Vigo: Galaxia, 1998, p. 105-121.

317. MARTINS, M. C. A emergência do português escrito na segunda metade do século XII. In: ALVAREZ BLANCO, R.; SANTAMARINA, A. (Eds.). Homenaxe a Fernando Tato Plaza. Santiago de Compostela: Instituto da Língua Galega, 2006.

318.

A língua latina: sua origem, variedades e desdobramentos. Disponível em:

http://www.filologia.org.br/vcnlf/anais\% 20v/civ6_01.htm. Acesso em: 10-09-2010.

319. MASSINI-CAGLIARI, G. (Org.). Anais do II Encontro de Estudos Diacrônicos do Português. Araraquara: UNESPFaculdade de Ciências e Letras, 2002.

320. et alii. (Orgs.). Estudos de linguística histórica do português. Araraquara: Cultura Acadêmica;Laboratório Editorial da UNESP, 2005.

321. MATEUS, M. H. M. A língua portuguesa - unidade e diversidade. In: Actas do $1^{o}$ Encontro da Associação Portuguesa de Linguística (Lisboa 1985). Lisboa: FLL, 1986, p. 145-163.

322. . Dialectos e variedades do português. In: MATEUS et alii, 2003, p. 41-51 
323. O português: caminhos da Investigação. In: DUARTE, I.; LEIRIA, I. (Eds.). Actas do Congresso Internacional sobre o Português (Lisboa 1994), Vol. I. Lisboa: Colibri, 1996, p. 7-22. ; NASCIMENTO, F. B. do. (Eds.). A língua portuguesa em mudança. Lisboa: Caminho, 2006.

325. MATTOS, Geraldo. Fundamentos históricos da língua portuguesa. Curitiba: IESDE BRASIL, 2009. [Com 12 videoaulas apresentadas por José Mario Botelho].

326. MATTOS E SILVA, R. V. A carta de Caminha: testemunho linguístico de 1500. Salvador: UFBA, 1996.

327. A mais antiga versão portuguesa dos "Quatro livros dos diálogos” de São Gregório. Edição crítica com introdução e índice geral das palavras lexicais. Dissertação de mestrado. São Paulo: Universidade de São Paulo, 1971, 4 v.

328. . Da sócio-história do português brasileiro para o ensino do português no Brasil hoje. In: AZEREDO, J. V. (Org.). Língua portuguesa em debate: conhecimento e ensino. Petrópolis: Vozes, 2000, p. 19-33.

329. Diversidade e unidade: a aventura linguística do português. Revista ICALP 11, 12-13, 1988, p. 60-72; 13-28 [transcr. em CASTRO, I. (selec.) 1991, p. 113-141.

330. . Ensaios para uma sócio-história do português brasileiro. São Paulo: Parábola, 2004. Estruturas trecentistas: elementos para uma gramática do português arcaico. Lisboa: Imprensa Nacional/Casa da Moeda, 1989.

332. . Ideias para a história do português brasileiro: fragmentos para uma composição posterior. In: CASTILHO (Org., 1998, p. 21-52).

333. 1991.

334. O português arcaico: fonologia, morfologia e sintaxe. São Paulo: Contexto, 2006. 
335. Contexto, 1994.

336. O português arcaico: uma aproximação. Lisboa: Imprensa Nacional-Casa da Moeda, 2008, $2 \mathrm{v}$.

337. O português são dois...: novas fronteiras, velhos problemas. São Paulo: Parábola, 2004.

338. O português são dois: variação, mudança, norma e a questão do ensino do português do Brasil. In: DUARTE, I.; LEIRIA, I. (Eds.). Actas do Congresso Internacional sobre o Português (Lisboa, 1994), Vol. II. Lisboa: Colibri, 1996, p. 375-401.

339. . Para a história do português brasileiro. V. II - primeiros estudos. São Paulo: Humanitas, 2001, 2 t.

340. _. Para uma caracterização do período arcaico do português. DELTA 10 (2), 1994, p. 247-276.

341. Pero e porém: mudanças em curso na fase arcaica da língua portuguesa. Boletim de Filologia. Lisboa, XXIX, p. $1290151,1984$.

342. - Reflexões e questionamentos para a constituição de corpora para o projeto Para a História do Português Brasileiro. In: DUARTE; CALLOU (Orgs., 2002, p. 17-28).

343. Resíduos arcaizantes em 1540: a propósito do uso variável de "ser/estar" e de "haver/ter" em estruturas possessivas no período arcaico do português. In: DUARTE, L. P., 1999, p. 234-245.

344. Sobre a mudança linguística: uma revisão histórica. Boletim de Filologia 26, 1981, p. 83-99.

345 . Sobre o Programa para a História da Língua Portuguesa (PROHPOR) e sua inserção no projeto nacional "Para a História do Português Brasileiro" (PHPB). In: RONCARATI; ABRAÇADO (Orgs., 2003, p. 30-38).

346. _. Tradição gramatical e gramática tradicional. 5. ed. São Paulo: Contexto, 2000. 
347. Um aspecto do auxiliar no português arcaico. Tulane Studies in Romance Languages and Litteratures. Tulane, 1981, n. 10, p. 93-109.

348. . Variação e mudança no português arcaico: ter ou haver em estruturas de posse. In: PEREIRA; PEREIRA (Eds., 1995, p. 299-311).

349. . (Org.). A carta de Caminha: testemunho linguístico de 1500. Salvador: UFBA, 1997.

350. ___ MACHADO FILHO, A. V. L. (Orgs.). O português quinhentista: estudos linguísticos. Salvador: UFBA/UEFS, 2002.

351. MATTOSO, J. Livro de Linhagens do Conde D. Pedro. PMH, Nova Série, II/1. Edição crítica de todo o texto, toma como base o fragmento da Ajuda na extensão que ele recobre. Lisboa: Academia das Ciências, 1980.

352. MAURER JR., T. H. A linguística histórica. Alfa 11, 1967, p. $19-42$.

353. USP, 1951.

354. ca, 1959.

355 . ca, 1967. . Gramática do latim vulgar. Rio de Janeiro: Acadêmi-

356. MEDEIROS, A. A. D. de. A língua portuguesa. Disponível em: http://www.linguaportuguesa.ufrn.br. Acesso em 10-092010.

357. MEGALE, H; OSAKABE, H. (Orgs.). Textos medievais portugueses e suas fontes. São Paulo: Humanitas, 1999.

358. MEIER, H. A evolução do português dentro do quadro das línguas ibero-românicas. Biblos 18, tomo II, 1943, p. 497-515.

359. A formação da língua portuguesa. In: . Ensaios de filologia românica. Lisboa: Revista de Portugal, 1948, p. 5-30. 
360. Sobre o superstrato visigótico no vocabulário hispanoportuguês. Boletim de Filologia 18 (=Actas do IX Congresso Internacional de Linguística Românica, Lisboa, 1959. Vol. I. Lisboa: Centro de Estudos Filológicos), 1961, p. 67-70.

361. MELO, G. C. de. A língua do Brasil. 2. ed. Rio de Janeiro: Fundação Getúlio Vargas, 1971. [1ª ed. Agir, 1946].

362. MENDONÇA, R. A influência africana no português do Brasil. Rio de Janeiro: Civilização Brasileira, 1973.

363. MENÉNDEZ PIDAL, R. Orígenes del Español. Estado linguístico de la Península Ibérica hasta el siglo XI. Madrid: EspasaCalpe, 1986.

364. 1952. . Toponímia prerromana hispana. Madrid: Gredos,

365. MERÊA, M. P. A versão Portuguesa das Flores de las Leyes de Jacóme Ruiz. Revista da Universidade de Coimbra 6, 1917, p. 341-371.

366. MESSNER, Dieter. História do léxico português. Heidelberg: Carl Winter/Universitätsverlag, 1990.

367. METTMANN, W. Cantigas de Santa Maria. Coimbra, 19591972, $4 \mathrm{v}$.

368. MIAZZI, M. L. F. Introdução à linguística românica. São Paulo: Cultrix, 1972.

369. MINGAS, A. A. Multiplicidade linguística: A língua portuguesa em Angola. In: DUARTE, I.; LEIRIA, I. (Eds.). Actas do XX Encontro Nacional da Associação Portuguesa de Linguística (Lisboa 2004). Lisboa: Colibri, 2005, p. 73-77.

370. MÓDOLO, M. Corpus diacrônico do português paulista. Campinas: IEL/UNICAMP, [no prelo].

371. __ Um corpus para a diacronia do português de São Paulo. São Paulo: USP, 1998.

372. MONTEAGUDO, H. Historia social da lingua galega. Vigo: Galaxia, 1999. 
373. MONTEIRO, C. Fundamentos clássicos do português do Brasil. Rio de Janeiro: Colégio Pedro II, 1958.

374. Português da Europa e português da América. Rio de Janeiro: Imprensa Nacional, 1952.

375. MONTEIRO, J. L. A ortografia de Álvaro Ferreira de Vera. Verba 19, 1992, p. 79-94.

376. . Variação no uso dos pronomes pessoais no português do Brasil. Verba 17, 1990, p. 145-157.

377. MORAIS-BARBOSA, J. A língua portuguesa no mundo. Lisboa: Agência Geral do Ultramar, 1959.

378. MUSSA, A. B. N. O papel das línguas africanas na história do português do Brasil. Rio de Janeiro: Universidade Federal do Rio de Janeiro, 1995.

379. NARO, A. J. Estudos diacrônicos. Petrópolis: Vozes, 1973.

380 . A história do $e$ e do $o$ em português. Um estudo de deriva linguística. In: (1973, p. 9-51).

381. ; SCHERRE, M. M. P. Origens do português brasileiro. [São Paulo]: Parábola, [2007].

382. ; SCHERRE, M. M. P. Sobre as origens do português popular do Brasil. DELTA 9, 1993, p. 437-454.

383. NASCENTES, A. Dicionário etimológico da língua portugue$s a$ : Vol. I: nomes comuns. Vol. II: nomes próprios. Rio de Janeiro: Francisco Alves/Acadêmica/Livros de Portugal/Livraria São José, 1952.

384. _. Elementos de filologia românica. Edição, revisão e notas de José Pereira da Silva. Rio de Janeiro: Botelho, 2009. 385 . Estudos filológicos. Organizado por Raimundo Barbadinho Neto. Rio de Janeiro: Academia Brasileira de Letras, 2003.

386. NEVES, M. H. M. A gramática: história, teoria, análise, ensino. São Paulo: UNESP, 2002. 
387. A vertente grega da gramática tradicional. 2. ed. rev. São Paulo: Hucitec/USP; São Paulo: UNESP.

388. NOLL, V. O português brasileiro: formação e contrastes. Trad. por Mário Eduardo Viaro. São Paulo: Globo, 2008.

389. NUNES, I. F. A demanda do Santo Graal. Lisboa: IN-CM, 1995.

390. NUNES, J. Ainda o famigerado "se". DELTA 11, 1995, p. 201240.

391. . O famigerado "se": uma análise sincrônica e diacrônica das construções com se apassivador e indeterminador. Dissertação de mestrado. Campinas: UNICAMP, 1990.

392. NUNES, J. H.; PETTER, M. (Orgs.). História do saber lexical e constituição de um léxico brasileiro. São Paulo: Humanitas, 2002.

393. NUNES, J. J. Compêndio de gramática histórica portuguesa: fonética e morfologia. 7. ed. Lisboa: Clássica, [1969].

394. . Crestomatia arcaica. 4. ed. Lisboa: Clássica, 1953.

395. NUNES, J. M. Direção de clitização, objeto nulo e pronome tônico na posição de objeto em português brasileiro. In: ROBERTS; KATO (Eds., 1996, p. 207-222).

396. OLIVEIRA, F. Gramática da linguagem portuguesa. Ed. crítica, semidiplomática e anastática de Amadeu Torres e Carlos Assunção. Lisboa: Academia Portuguesa de História, 2000.

397. OliVEIRA, G. M.; OLIVEIRA, S. M. Política linguística, política historiográfica: epistemologia e escrita da história da(s) língua(s) a propósito da língua portuguesa no Brasil meridional (1759-1830). Tese de doutorado. Campinas: UNICAMP, 2004.

398.

Linguisticas para America Latina. Acta del Congreso Interna Linguísticas para América Latina. Acta del Congreso Internacional [1997]. Buenos Aires: Universidad de Buenos Aires/Faculdad de Filosofá y Letras, Instituto de Linguística, vol. 2, p. 405-416. 
399. Última fronteira: a língua portuguesa no Brasil meridional: reflexões sobre um corpus linguístico diacrônico. In: CASTILHO (Org., 1998, p. 211-228).

400. __ U Última fronteira: história da língua portuguesa no Brasil meridional (1680-1830). In: GROSSE; ZIMMEMANN (Eds., 2000, p. 345-376).

401. OLIVEIRA, K. Negros e escrita no Brasil do séc. XIX. Salvador: UFBA, 2006.

402. __ Textos escritos por africanos e afrodescendentes na Bahia no século XIX: fontes do nosso latim vulgar? Salvador: UFBA, 2003.

403. OlIVEIRA, M. de. (Org.). Língua portuguesa em São Paulo: 450 anos. São Paulo: Humanitas, 2006.

404. OLIVEIRA, M. H. A. Língua portuguesa em Moçambique. Disponível em:

http://www.filologia.org.br/venlf/anais\%20v/civ6_01.htm. Acesso em: 10-09-2010.

405. ORIGEM da língua portuguesa. Vídeos disponíveis em: http://www.youtube.com/results?search_query=\%220rige m+da+L\% C3\% ADngua+Portuguesa \% 22\&aq=f. Acesso em: 10-09-2010.

406. PACHECO, C. A. O problema da periodização. Disponível em: http://www.filologia.org.br/soletras/4/07.htm. Acesso em: 10-09-2010.

407. PACHECO, C. M. G. Aspectos históricos de normatização ortográfica e o trabalho com a ortografia na escola. In: HAYE (Org., 1995, p. 63-72).

408. PÁDUA, M. P. C. M. de. A ordem das palavras no português arcaico. Coimbra: Faculdade de Letras da Universidade de Coimbra/Instituto de Estudos Românicos, 1960.

409. PAGOTTO, E. G. A posição dos clíticos em português: um estudo diacrônico. Campinas: Universidade Estadual de Campinas, 1992. 
410. PAIS, C. T. Sincronia, diacronia, pancronia: articulações das ciências da linguagem na pós-modernidade: homenagem ao eminente gramático Othon Moacyr Garcia. Disponível em:

http://www.filologia.org.br/xiicnlf/resumos/PDF/Sincronia, \%20diacronia,\% 20pancronia\%20articula\%C3\% A7\% C3\% B5es\% 20das\%20ci\% C3\%A Ancias\% 20da\% 20linguagem\% 20na\% 20p\% C3\%B3smodernidade\% 20-\%20CIDMAR.pdf. Acesso em: 10-092010.

411. PAIVA, M. História da língua portuguesa. Disponível em: http://www.linguaportuguesa.net/principal.htm . Acesso em 10-09-2010.

412. PAIVA, M. H. Variação e evolução da palavra gráfica. In: CASTRO, I. (Ed.). Actas do XII Encontro Nacional da Associação Portuguesa de Linguística (Braga / Guimarães 1996), Vol. II. Lisboa: Colibri, 1997, p. 233-252

413. . Vernaculidade versus relatinização: o testemunho dos gramáticos portugueses quinhentistas. In: Actas do $1^{\circ}$ Encontro da Associação Portuguesa de Linguística (Lisboa 1985). Lisboa: FLL, 1986, p. 375-397

414. PANTE, M. R. Abordagem dos morfemas derivacionais empregados nas "Cantigas d'amigo galego-portuguesas". Disponível em:

http://www.filologia.org.br/revista/40suple/abordagem_dos morfemas.pdf.

415. PARKINSON, S. Aspectos teóricos da história das vogais nasais portuguesas. In: CASTRO, I. (ed.). Actas do XII Encontro Nacional da Associação Portuguesa de Linguística (Braga / Guimarães 1996), Vol. II. Lisboa: Colibri, 1997, p. 253-272.

416. . Os tabeliães de 1290 e a dialectologia medieval portuguesa. In: PEREIRA, C. C.; PEREIRA, P. R. D. (Eds.), Miscelânea de Estudos Linguísticos, Filológicos e Literários. In Memoriam Celso Cunha. Rio de Janeiro: Nova Fronteira, 1995, p. 667-676. 
417. Final nasals in the Galician-Portuguese 'cancioneiros. In: MACKENZIE, D; MICHAEL, I. (Eds.) Hispanic Linguistic Studies. In Honour of F. W. Hodcroft. Llangrannog, Dolphin, 1993, p. 51-62.

418. PAUL, H. Princípios fundamentais da história da língua. Trad. Maria Luísa Schemann. Lisboa: Fundação Calouste Gulbenkian, 1970.

419. PEDRO, S. De Noticia de Torto. Dissertação de Mestrado. Lisboa: Universidade de Lisboa, Faculdade de Letras, 1994.

420. PENHA, J. A. P. A teoria do português do Brasil como modalidade arcaizante. Araraquara: Faculdade de Filosofia, Ciências e Letras, 1970, 2 v.

421. PENHA, H. M. M. M. O emprego de ele-acusativo: do português brasileiro ao latim. In: COHEN; RAMOS (Orgs., 2002, p. 67-82).

422. PEREIRA, C. C.; PEREIRA, P. R. D. (Orgs. e Coords.). Miscelânea de estudos linguísticos, filológicos e literários in memoriam Celso Cunha. Rio de Janeiro: Nova Fronteira, 1995.

423. PEREIRA, D. O ensino da língua portuguesa a minorias linguísticas de origem caboverdiana. In: DUARTE, I; LEIRIA, I. (Eds.). Actas do Congresso Internacional sobre o Português (Lisboa 1994), Vol. I. Lisboa: Colibri, 1996, p. 53-80.

424. PEREIRA, E. C. Gramática histórica. São Paulo: Cia. Ed. Nacional, 1933.

425. PEREIRA, E. S.; ALVES, I. M. Diacronia no Brasil colonial: terminologia da economia. Disponível em:

http://www.filologia.org.br/xiv_cnlf/resumos/diacronia_no brasil_colonial_ELIANE_IEDA.pdf. Acesso em: 10-09-2010.

426. [PEREIRA] FANHA, D. Aspectos do contacto entre o português e o crioulo de Cabo Verde. In: CINTRA, L. F. L. et alii. (Eds.). Actas do Congresso sobre a situação actual da língua portuguesa no mundo (Lisboa 1983), Vol. II. Lisboa: ICALP, 1988, p. 292-310. 
427. PEZATTI, E. G. O patrimônio visigodo da língua portuguesa. Coimbra: Publicações do Instituto Alemão da Universidade de Coimbra, 1942.

428. PIEL, J. M. A demanda do Santo Graal. Edição concluída por Irene Freire Nunes, com Introdução de Ivo Castro. Lisboa: INCM, 1988.

429. . Estudos de linguística histórica galego-portuguesa. Lisboa: Imprensa Nacional/Casa da Moeda, 1989.

430. __ Os nomes germânicos na toponímia portuguesa. Boletim de Filologia 2, 1933, p. 105-140 e 224-240; 3, 1934-1935, p. $37-53,218-242$ e $367-394 ; 4,1936$, p. 24-56, 307-322; 5, 1937 , p. $35-57,277-288 ; 6,1939$, p. 65-86, 329-350; 7, 1940, p. 357-386.

431. O patrimônio visigodo da língua portuguesa. Coimbra: Publicações do Instituto Alemão da Universidade de Coimbra, 1942.

432. PIMENTA, A. Fuero Real de Afonso X, o Sábio: versão portuguesa do séc. XIII. Lisboa: IPAC, 1946.

433. PINTO, A. A. A neutralização da oposição fonológica $v / b \mathrm{em}$ português: estudo sincrónico e diacrónico. Biblos 56, 1980, p. 599-651.

434. PINHO, S. T. André de Resende e a relatinização ortográfica da língua portuguesa. In: CAVALIERE (Org., 2008, p. 191-210).

435. PINILLA, A. RIGONI, C.; INDIANI, M. T. História da língua portuguesa. Disponível em: http://acd.ufrj.br/ pead/tema05/por-tm05.html. Acesso em: 10-09-2010.

436. PINTO, E. P. Língua escrita no Brasil. São Paulo: Ática, 1986.

437. $\ldots$ português popular escrito. São Paulo: Contexto, 1990.

438. _ (Org.). O português do Brasil: textos críticos e teóricos. V. I: 1820-1920. São Paulo: Edusp, 1978. 
439. (Org.). O português do Brasil: textos críticos e teóricos. V. II: 1920-1945. São Paulo: Edusp, 1981.

440. POGGIO, R. M. G. F. Processos de gramaticalização de preposições do latim ao português: uma abordagem funcionalista. Salvador: Edufba, 2002.

441. Portugaliae Monumenta Historica, Scriptores, I, fasc. II. Os Livros de Linhagens: III. Lisboa, 1856.

442. Portugaliae Monumenta Historica, Leges et Consuetudines, I e II. 1856 e 1868.

443. Portugaliae Monumenta Historica, Inquisitiones I e II. 1888 e 1917.

444. PRESTES, M. L. M. A língua portuguesa em uma perspectiva histórica: propostas de trabalho em um processo dinâmico, para os três níveis de ensino. Disponível em:

http://www.filologia.org.br/revista/artigo/7(19)04.htm. Acesso em: 10-09-2010.

445. QUENTAL, V. As gramáticas do século XVI: a questão da norma. In: HAYE (Org., 1995, p. 145-150).

446. RAMOS, J. A alternância "não" e "num" no dialeto mineiro. In: COHEN; RAMOS (Orgs., 2002, p. 155-168).

447. . História social do português brasileiro: perspectivas. In: CASTILHO (Org., 1998, p. 153-167).

448. ___ O surgimento de um novo clítico no português brasileiro: análise quantitativa e qualitativa da forma cê. In: GÄRTNER; SCHÖNBERGER (Eds., 2000, p. 181-190).

449. __ Seleção do corpus para o estudo da língua portuguesa na Capitania de Minas Gerais no século XVIII. In: MATTOS E SILVA (Org., 2001, t. 2, p. 423-434).

450. __ Sintagmas possessivos: o percurso diacrônico de perda de [aNP] pleno no português brasileiro. In: MASSINICAGLIARI et alii (Orgs., 2005).

451. . Um plano para a sintaxe diacrônica do português brasileiro. In: CASTILHO (Org., 1998, p. 79-88). 
452. ; ALKMIN, M. A. (Orgs.). Para a história do português brasileiro. V. V - estudos sobre mudança linguística e história social. Belo Horizonte: Faculdade de Letras da Universidade Federal de Minas Gerais, 2007.

453. ; VENÂNCIO, R. Topônimos mineiros: uma fonte para a história social da língua portuguesa. In: DUARTE; CALLOU (Orgs., 2002, p. 113-124).

454. RAMOS, M. A. A separação silábica na cópia da poesia lírica galego-portuguesa: outro indício de antecedentes musicais. In: PEREIRA; PEREIRA (Coords., 1995, p. 703-719).

455. RÉVAH, I. S. Comment et jusqu'à quel point les parlers brésiliens permettent-ils de reconstituer le système phonétique des parlers portugais des XVIe-XVIIe siècles?. In: Actas do III Colóquio Internacional de Estudos Luso-Brasileiros. Lisboa, 1959, p. 273-291.

456. L'évolution de la prononciation au Portugal et au Brésil du XVIe siècle à nos jours. In: Anais do Primeiro Congresso Brasileiro de Língua Falada no Teatro. Bahia, 1956, p. 387402

457. RIBEIRO, E. C. Serões grammaticais, ou, nova grammatica portugueza. Salvador: Dois mundos, 1915.

458. RIBEIRO, I. A formação dos tempos compostos: a evolução histórica das formas "ter", "haver" e "ser". In: ROBERTS; KATO (Orgs., 1993, p. 343-386).

459. . A sintaxe da ordem no português arcaico: o efeito V2. Campinas: UNICAMP, 1995.

460. __ Sobre a perda da inversão do sujeito no português brasileiro. In: MATTOS E SILVA (Org., 2001, t. 1, p. 91-126).

461. RIBEIRO, J. P. Dissertações chronologicas e críticas sobre a história e a jurisprudência eclesiástica e civil de Portugal. Dissertação V. Lisboa: Real Academia das Sciencias, 1860.

462. RIBEIRO, M. J. F. H. Edição dos documentos medievais do cartório de Santa Eufémia de Ferreira de Aves. Dissertação de 
Mestrado. Lisboa: Universidade de Lisboa, Faculdade de Letras, 1994.

463. RIBEIRO, M. P. A modernidade da gramática histórica. Disponível em: http://www.filologia.org.br/vcnlf/anais\% 20v/civ6 01.htm. Acesso em: 10-09-2010.

464. A importância da fonologia sincrônica no estudo da diacronia. Disponível em:

http://www.filologia.org.br/viiicnlf/anais/caderno1001.html. Acesso em: 10-09-2010.

465. RIBEIRO, O. A propósito de áreas lexicais no território português (algumas reflexões acerca do seu condicionamento). In: CINTRA, L. F. L. 1983, p. 35-54.

466. RIBEIRO, S. N. O léxico em movimento: comentários sobre neologia e neologismos. Disponível em:

http://www.filologia.org.br/viiicnlf/anais/caderno13-

18.html. Acesso em: 10-09-2010.

467. ROBERTS, I. O português brasileiro no contexto das línguas românicas. In: .; KATO. (Eds., 1993, p. 409-425).

468. ROBERTS, I; KATO, M. A. (Orgs.). Português brasileiro: uma viagem diacrônica. Campinas: UNICAMP, 1993.

469. RODRIGUES, A. C. S. Concordância verbal, sociolinguística e história do português brasileiro. Fórum Linguístico, V. 4, N. 1, p. 115-143, jul. 2007, Florianópolis.

470. RODRIGUES, C. Dos costumes de Santarém. Dissertação de Mestrado. Lisboa: FLL, 1990.

471. RODRIGUES, R. N. Os africanos no Brasil. São Paulo: Cia. Ed. Nacional, 1945.

472. RODRIGUEZ, J. L. A propósito de la partícula per intensiva o perfectiva en la lengua medieval gallego-portuguesa. Verba 3 , 1976, p. 295-308

473. . Castelhanismos no galego-português de Afonso X, o Sábio. Boletim de Filologia 28, 1983, p. 7-19 
474. De castelhano para galego-português: as traduções medievais. In: ALVAREZ, R.; VILAVEDRA, D. (Eds.) Cinguidos por unha arela común. Homenaxe ó profesor Xesús Alonso Montero. Vol. II. Santiago de Compostela: Universidade de Santiago, 1999, p. 1285-1299.

475. RONCARATI, C.; ABRAÇADO, J. (Orgs.). Português brasileiro: contato linguístico, heterogeneidade e história. Rio de Janeiro: 7Letras/FAPERJ, vol. I, 2003.

476. ; __ Português brasileiro II: contato linguístico, heterogeneidade e história. Niterói: UFF, 2008.

477. ROSSI, N. (Dir.) et alii. Livro das Aves. Reprodução facsimilar do manuscrito do século XIV, introdução, leitura crítica, notas e glossário. Rio de Janeiro: Instituto Nacional do Livro, 1965.

478. ROUDIL, J. (Dir.). Edição do manuscrito português das Flores de Dereyto. In: La tradition d'écriture des "Flores de Derecho”. Construction et étude. Tome I. Vol. I. Publ. du Séminaire d'Etudes Médiévales Hispaniques de l'Université Paris 13, 2000, p. 200-297.

479. SAID ALI, M. Gramática histórica da língua portuguesa. Ed. rev. por Mário Eduardo Viaro. São Paulo: Melhoramentos, 2002.

480. SALLES, M. Arquivos paulistanos de interesse para a história do português de São Paulo. In: MATTOS E SILVA (Org., 2001, t. 2, p. 435-442).

481.

Pronomes de tratamento do interlocutor no português brasileiro: um estudo de pragmática histórica. Tese de doutorado. São Paulo: USP, 2001.

482. SANTOS, M. J. M. Importação lexical e estruturação semântica. Os arabismos na língua portuguesa. Biblos 56 (Homenagem a Joaquim de Carvalho), 1980, p. 573-598.

483. ___ Nota sobre o movimento quinhentista de defesa e ilustração das línguas vulgares. Biblos 5, 1975, p. 517-528. 
484. SCHERRE, M. M. P. Aspectos sincrônicos e diacrônicos do imperativo gramatical no português brasileiro. Alfa 51, 2007, p. 189-222.

485. SCHLIEBEN-LANGE, B. História do falar e história da linguística. Trad. F. Tarallo et alii. Campinas: UNICAMP, 1993.

486. SCHMIDT-RIESE, R. Periodização do português brasileiro: algumas considerações. In: DUARTE; CALLOU (Orgs., 2002, p. 179-196).

487. SCHRADER-KNIFFKI, M.; GARCÍA, L. M. (Eds.). La Romania en interacción: entre historia, contacto y política. Ensayos en homenaje a Klaus Zimmermann. Madrid: Iberoamericana; Frankfurt am Main: Vervuert, 2007.

488. SEABRA, M. C. T. C. de. Uma abordagem diacrônica das construções de tópico em português. Belo Horizonte: Universidade Federal de Minas Gerais, 1994.

489. SEPÚLVEDA NETTO, M. S. Ser/estar: um estudo de variação e mudança em curso no português antigo. Dissertação de mestrado. Salvador: UFBA, 1989.

490. SILVA, A. C. S. O passado, o presente e o futuro da língua portuguesa. Disponível em:

http://www.filologia.org.br/iijnlflp/textos/O_passado_o_pre $\underline{\text { sen- }}$

te e $0 \% 20$ futuro\% 20da\% 201\% C3\%ADngua \% 20portugue sa\% 20-\% 20ANA \% 20CRISTINA.pdf. Acesso em: 10-092010.

491. SILVA, A. M. Diccionario da lingua portugueza. Composto pelo Padre D. Rafael Bluteau, reformado e acrescentado. Lisboa: Ferreira, 1789.

492. SILVA, J. F.; ORÓSIO, P. Introdução à história da língua portuguesa: dos factores externos à dinâmica do sistema linguístico. Chamusca: Cosmos, 2008.

493. SILVA, J. P.. A nova ortografia da língua portuguesa. 2. ed. rev. e atual. Niterói: Impetus, 2010. 
494. . Contribuição árabe na formação do português. Disponível em: http://www.filologia.org.br/vcnlf/anais\% 20v/civ6_01.htm. Acesso em: 10-09-2010.

495. . Gramática histórica da língua portuguesa. Rio de Janeiro: O Autor, 2010.

496. . (Org.). Cinco teses de Evanildo Bechara. Rio de Janeiro: Botelho, 2009.

497. SILVA, L. A. (Org.). A língua que falamos: português. História, variação e discurso. São Paulo: Globo, 2005.

498. SILVA, P. V. M. Do latim ao brasileiro: panorama evolutivo da língua portuguesa. Disponível em:

http://www.filologia.org.br/revista/40/DO\%20LATIM\%20 AO\% 20BRASILEIRO.pdf. Acesso em: 10-09-2010.

499. SILVA, R. J. da. A oração infinitiva no português arcaico. Disponível em:

http://www.filologia.org.br/viiicnlf/anais/caderno1003.html. Acesso em: 10-09-2010.

500. SILVA NETO, S. da. Diálogos de São Gregório. Edição crítica segundo os três manuscritos conhecidos. Coimbra: Atlântida, 1950.

501. Fontes do latim vulgar. Rio de Janeiro: Acadêmica, 1950.

502. . Fragmentos de uma tradução medieval portuguesa (fins do século XIV) de um Livro das Aves, de autor anônimo. In: Textos medievais portugueses e seus problemas. Rio de Janeiro: Casa de Rui Barbosa, 1956, p. 40-45; 104-105.

503. . História da língua portuguesa. Rio de Janeiro: Livros de Portugal, 1950.

504. . Manual de filologia portuguesa. 2. ed. Rio de Janeiro: Acadêmica, 1957.

505. . Regra de São Bento. Edição crítica da mais antiga versão portuguesa acompanhada de breves notas filológicas. Revis- 
ta Brasileira de Filologia 5, I-II. Rio de Janeiro, 1959-1960, p. 21-46.

506. Vida de S. Nicolau. Boletim de Filologia A.2. Rio de Janeiro, 1947, p. 233-238.

507. __ Textos medievais portugueses e seus problemas. Rio de Janeiro: Casa de Rui Barbosa, 1956.

508. SILVEIRA, A. L. D. História do verbo "ser": do latim ao português. 2. ed. Natal: Universitária, 1980.

509. SILVEIRA, O. G. A filologia no Brasil. In: FREITAS, 1996, p. 119-128.

510. . A Gramática de Fernão d'Oliveyra. In: FREITAS, 1996, p. 102-118.

511. A nova maneyra de fallar. In: FREITAS, 1996, p. 129135.

512. SOUTO CABO, J. A. Caracterizaçom dialectal da Galiza na idade média. In: HILTY, G. (Ed.) Actes du XXe Congrès International de Linguistique et Philologie Romanes (Zurich 1992), tome II, 1993, p. 531-545.

513. Dinâmicas da escrita romance na primeira metade do século XIII. In: MENDES, A.; FREITAS, T. (Eds.) Actas do XVIII Encontro Nacional da APL (Porto 2002) Lisboa, Colibri, 2003, p. $795-814$.

514. Nas origens da expressão escrita galego-portuguesa. Documentos do século XII. Diacrítica 17, 2003, p. 329-385.

515. Novas perspectivas sobre a génese da scripta romance na área galego-portuguesa. Textos e contextos. Aemilianense I, Logroño, 2004, p. 569-599.

516. . O "Testamento de Estêvão Peres" (1230). Aproximação à primeira escrita galego-portuguesa na Galiza. Revista de Filología Románica 13, Madrid, 1996, p. 123-149.

517. SOUZA, J. Vestígios da língua arábica em Portugal. Lisboa: Officina da Academia Real das Sciencias de Lisboa, 1830. 
518. SPINA, S. (Org.). História da língua portuguesa. Cotia: Ateliê, 2008. [1 ${ }^{a}$ ed. São Paulo: Ática, 1988, 6 v.].

519. SPONER, M. Documentos antigos de Galicia. Anuari de l'Oficina Romànica de Linguística. Literatura 7, 1934, p. 113-192.

520. TARALLO, F. (Org.). Diagnosticando uma gramática brasileira: o português d'aquém e d'além-mar ao final do século XIX. In: ROBERTS; KATO (Orgs., 1993, p. 69-106).

521. CAMP, 1989.

522. . Sobre a alegada origem crioula do português brasileiro: mudanças sintáticas aleatórias. In: ROBERTS; KATO (Orgs., 1993, p. 35-68).

523. Tempos linguísticos: itinerário histórico da língua portuguesa. São Paulo: Ática, 1990.

524. TATO PLAZA, F. R. Dous documentos en galego de 1229? In: CASTRO, I. (Ed.). Actas do XII Encontro Nacional da Associação Portuguesa de Linguística (Braga / Guimarães 1996) Vol. II. Lisboa: Colibri, 1997, p. 297-302.

525. TEIXEIRA, E. P. Por onde andava o "tu" no final do séc. XIX? Revista da Abralin 7 (1), 2008, p. 161-175.

526. TEYSSIER, P. Especificidade do português. In: DUARTE, I.; LEIRIA, I. (Eds.). Actas do Congresso Internacional sobre o Português (Lisboa 1994), Vol. II. Lisboa: Colibri, 1996, p. 191207.

527. . História da língua portuguesa. Trad. de Celso Cunha. São Paulo: Martins, 2007.

528. Jerónimo Cardoso et les origines de la lexicographie portugaise. Bulletin des Études Portugaises et Brésiliennes 41, 1980, p. 7-32.

529. La langue de Gil Vicente. Paris: Klincksiech, 1959.

530. __ La prononciation des voyelles portugaises au XVIe siècle d'après le système orthographique de João de Barros. In: Atti del Secondo Convegno Italiano di Studi Filologici e Storici 
Portoghesi e Brasiliani, Annali dell' Instituto Universitario $O$ rientale. Sezione Romanza, VIII, 1966, p. 127-198.

531. Le système des déictiques spatiaux en portugais aux XIVe, XVe et XVIe siècles. Cahiers de Linguistique Hispanique Médiévale 6, 1981, p. 5-69.

532. THOMAZ, L. F. A língua portuguesa em Timor. In: CINTRA, L. F. L. et al. (Eds.). Actas do Congresso sobre a situação actual da língua portuguesa no mundo (Lisboa 1983), Vol. I. Lisboa: ICALP, 1985, p. 313-338.

533. THUN, H. O comportamento linguístico dos brasiguaios no Paraguai vistos a partir do material do Atlas Guaraní-Románico. In: DIETRICH; NOLL (Orgs., 2004, p. 169-191).

534. TOLEDO NETO, S. A. Subsídios Para a fixação de normas de transcrição de textos para estudos linguísticos - III. In: MATTOS E SILVA (Org., 2001, t. 2, p. 539-549).

535. _ Constituição de corpus de documentação dos séculos XVII, XVIII e XIX (PHPB-SP). In: DUARTE; CALLOU (Orgs., 2002, p. 39-48).

536. TOMÉ, J. L. P. Fragmento de un "Livro de Tristán" galaicoportuguês. Ed. e estudo. Santiago de Compostela: Cons. Sup. de Investigaciones Científicas, 1962.

537. TORRES MORAIS, M. A. C. Aspectos da história das palavras negativas no português. In: MATTOS E SILVA (Org., 2001, t. 1, p. 149-204).

538. Aspectos diacrônicos do movimento do verbo, estrutura da frase e caso nominativo no português do Brasil. In: ROBERTS; KATO (Orgs., 1993, p. 263-306).

539. ___ Para uma abordagem diacrônica do português brasileiro. In: CASTILHO (Org., 1998, p. 121-142).

540. __ Rastreando aspectos gramaticais e sócio-históricos do português brasileiro em anúncios de jornais do século XIX. In: RAMOS; ALKMIN (Orgs., 2007) 
541. TORRES MORAIS, M. A. C.; ANDRADE, M. L. C. V. O. (Orgs.). História do português paulista. Campinas: UNICAMP/FAPESP, 2009.

542. TROUCHE, L. M. G. O Marquês de Pombal e a implantação da língua portuguesa no Brasil: reflexões sobre a proposta do diretório de 1757. Disponível em:

http://www.filologia.org.br/anais/anais\%20iv/civ12_9.htm. Acesso em: 10-09-2010.

543. UCHÔA, C. E. F. A linguagem: teoria, ensino e historiografia. Rio de Janeiro: Nova Fronteira, 2008.

544. VALLE, R. do. Considerações sobre a Peregrinatio Aetheriae. Org. e ed. de José Pereira da Silva. Rio de Janeiro: Botelho, 2008.

545 . . História da língua e romanística na bibliografia de Evanildo Bechara. In: CAVALIERE (Org., 2008, p. 171-185).

546. VALVERDE, J. F. Cantigas de Santa Maria. Madrid: Castalia, 1985.

547. VASCONCELlOS, J. L. Esquisse d'une Dialectologie Portugaise. ed. crítica de M. Adelaide Valle Cintra.. Lisboa: INIC, 1987.

548. ___ Lições de filologia portuguesa. Rio de Janeiro: Livros de Portugal, 1964.

549. VASCONCELOS, C. M. Cancioneiro da Ajuda. Edição crítica. Halle, 1904.

550. __ Lições de filologia portuguesa segundo as prelecções feitas aos cursos de 1911-12 e de 1912-13. Seguidas das Lições Práticas de Português Arcaico. Lisboa: Dina Livro, 1977.

551. VERA, Á. F. Orthographia ou Modo para escrever certo na lingua portuguesa. Lisboa: Mathias Rodriguez, 1631.

552. VERDELHO, E. Livro das obras de Garcia de Resende. Edição crítica, estudo textológico e linguístico. Lisboa: Fundação Calouste Gulbenkian, 1994. 
553. Sobre a língua portuguesa do séc. XVII. Estudos realizados e trabalhos em curso. In: CASTRO, I. (ed.), Actas do XII Encontro Nacional da Associação Portuguesa de Linguística (Braga / Guimarães 1996), Vol. II. Lisboa: Colibri, 1997, p. 325-339.

554. VERDELHO, T. Latinização na história da língua portuguesa o testemunho dos dicionários. Arquivos do Centro Cultural Português 23. Lisboa / Paris: Fundação Calouste Gulbenkian, 1987, p. 157-187.

555. Origens da gramaticografia e da lexicografia latinoportuguesas. Aveiro: INIC, 1995.

556. VIANA, A. R. G. Essai de phonétique et de phonologie de la langue portugaise, d'après le dialecte de Lisbonne. In: . Estudos de fonética portuguesa. Lisboa: Imprensa Nacional-Casa da Moeda, 1973, p. 83-152.

557. Exposição da pronúncia normal portuguesa para uso de nacionais e estrangeiros. In: . Estudos de fonética portuguesa. Lisboa: Imprensa Nacional-Casa da Moeda, 1973, p. 153257.

558. VIARO, M. E. Das preposições latinas às do português e do romeno: derivações semânticas. São Paulo: USP, 1994.

559. . Por trás das palavras. São Paulo: Globo, 2004.

560. _ _ Reflexões teóricas acerca da reconstrução lexical do português antigo paulista. In: CASTILHO (Org., 2009, p. 737744).

561. VIDOS, B. E. Manual de linguística românica. Tradução de José Pereira da Silva. Apresentação de Evanildo Bechara. Rio de Janeiro: Eduerj, 1996.

562. VITERBO, Fr. J. S. R. Elucidário das palavras, termos e frases que em Portugal antigamente se usaram e que hoje regularmente se ignoram. Edição crítica baseada nos manuscritos e originais de Viterbo por Mário Fiúza. Porto; Lisboa: Civilização, 1962 e 1966, 2 v. 
563. VITRAL, L. A evolução da negação no português brasileiro: sintaxe formal e gramaticalização. In: GÄRTNER; HUNDT; SCHÖNBERGER (Eds., 2000, p. 175-180).

564. A forma "cê" e a noção de gramaticalização. Revista de Estudos da Linguagem 4 (1), 1996, p. 115-124.

565. . Língua geral versus língua portuguesa: a influência do "processo civilizatório". In: MATTOS E SILVA (Org., 2001, t. 2, p. 275-302).

566. ; RAMOS, J. Gramaticalização de "você": um processo de perda de informação semântica? Filologia e Linguística Portuguesa 3, 1999, p. 55-88.

567. VOGT, C.; FRY, P. A África no Brasil. Campinas: UNICAMP; São Paulo: Companhia das Letras, 1996.

568. . Rios de Cristal: contos e desencontros de línguas africanas no Brasil. Cadernos de Estudos Linguísticos 8, 1985, p. 109-128.

569. WALTER, H. A aventura das línguas no ocidente: origem, história e geografia. São Paulo: Mandarim, 1997.

570. WIKIPÉDIA. História da língua portuguesa. Disponível em: http://pt.wikipedia.org/wiki/Hist\%C3\%B3ria_da_1\% C3\% ADngua_portuguesa. Acesso em: 10-09-2010.

571. WILLIAMS, E. Do latim ao português. Trad. Antônio Houaiss. Rio de Janeiro: Instituto Nacional do Livro, 1961.

572. WITTMANN, L. H.; PEREIRA, M. J. Português europeu e português brasileiro: alguns contrastes. In: Actas do X Encontro Nacional da Associação Portuguesa de Linguística (Évora 1994). Lisboa: Colibri, 1995, p. 613-627.

573. ZÁGARI, M. R. L. Fonologia diacrônica do português. Juiz de Fora: Universidade Federal de Juiz de Fora, 1988. 